\title{
MECHANISMS FOR TEMPORAL CHANGE IN PHYTOPLANKTON COMPOSITION IN SAN LUIS OBISPO BAY CALIFORNIA
}

\author{
A Thesis \\ Presented to the \\ Faculty of \\ California State Polytechnic University, San Luis Obispo \\ In partial fulfillment \\ of the Requirements for the Degree \\ Master of Science \\ In \\ Biological Sciences
}

\author{
by \\ Marc Timothy Tognazzini \\ August 2009
}


(C)2009

Marc Timothy Tognazzini

ALL RIGHTS RESERVED 


\title{
COMMITTEE MEMBERSHIP
}

TITLE: MECHANISMS FOR TEMPORAL CHANGE IN PHYTOPLANKTON COMPOSITION IN SAN LUIS OBISPO BAY CALIFORNIA

\author{
AUTHOR: Marc Timothy Tognazzini \\ DATE SUBMITTED: August 2009
}

COMMITTEE CHAIR: Mark Moline, Ph.D.

COMMITTEE MEMBER: Dean Wendt, Ph.D.

COMMITTEE MEMBER: Nikki Adams, Ph.D. 


\section{ABSTRACT \\ MECHANISMS FOR TEMPORAL CHANGE IN PHYTOPLANKTON COMPOSITION IN SAN LUIS OBISPO BAY CALIFORNIA}

\section{Marc Timothy Tognazzini}

Coastal topography and more specifically, the impact of local hydrography can significantly influence phytoplankton dynamics along the California coast. In San Luis Obispo Bay California, the local hydrography is influenced by the presence of a lee and proposed upwelling shadow in the northwest corner of the bay. These conditions allow for periods of unperturbed phytoplankton growth creating phytoplankton incubation areas. Phytoplankton dynamics including accumulation, advection, and composition were examined in San Luis Obispo Bay California from January to June 2004 using all the primary techniques of ocean monitoring encompassed in the coastal module of the Global Ocean Observing System. These techniques included remote sensing, autonomous sensing, discrete sampling and laboratory analysis. Results demonstrated that composition in the bay followed the typical seasonal shifts seen along the California coast. These findings reveal a community that was primarily dominated by dinoflagellates during the winter months giving way to a diatom dominated community in the spring and summer as upwelling season reached the coast. The model of cyclic phytoplankton accumulation and advection was shown to be valid and driven by both coastal upwelling as well as poleward displacement during periods of relaxation. In addition, due to presence of a stratified subsurface chlorophyll layer, the depth component was shown to be vital when attempting to access and sample phytoplankton communities in the bay. 


\section{TABLE OF CONTENTS}

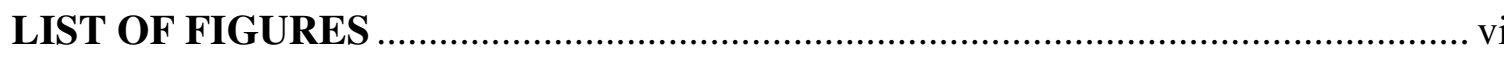

INTRODUCTION

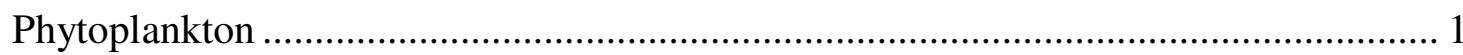

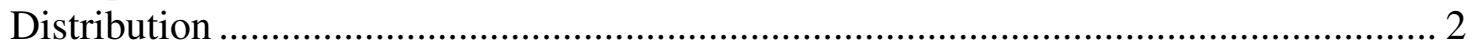

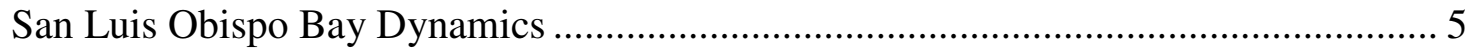

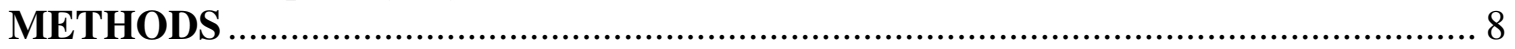

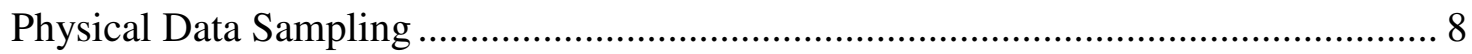

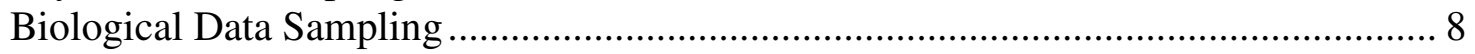

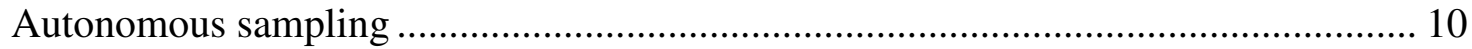

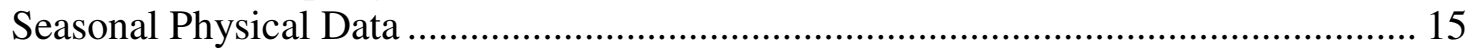

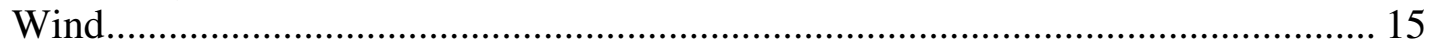

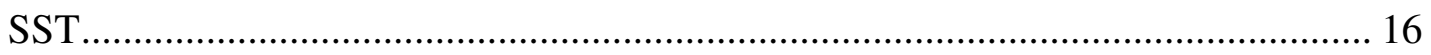

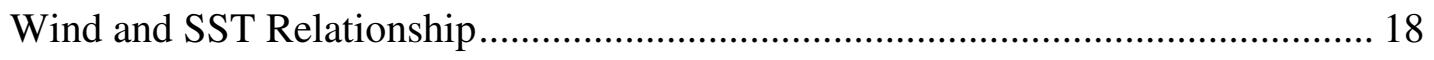

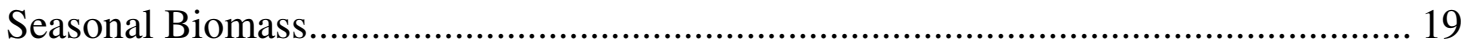

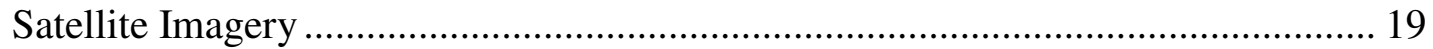

Pigmentation, Identification and Quantification................................................. 20

Seasonal Community Structure............................................................................... 22

Pigmentation, Identification and Quantification.................................................... 22

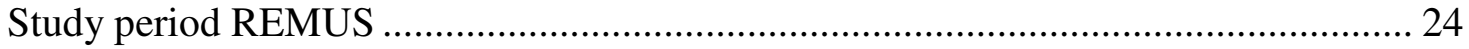

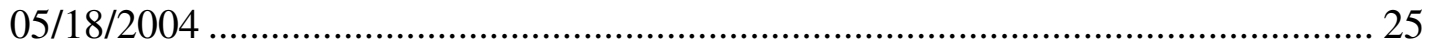

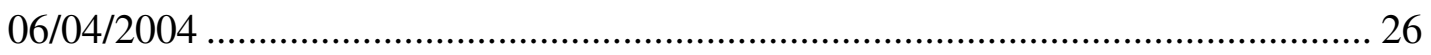

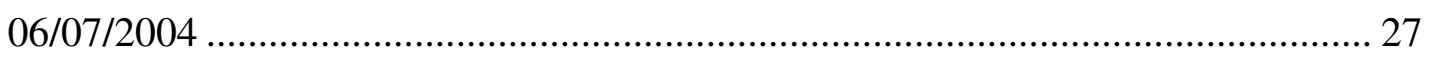

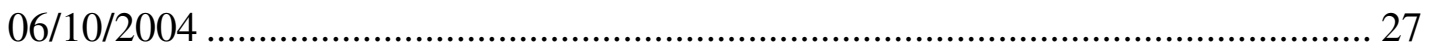

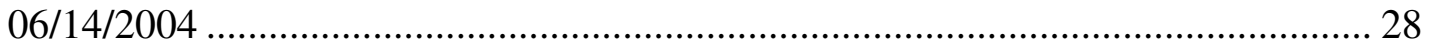

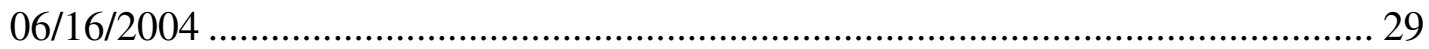

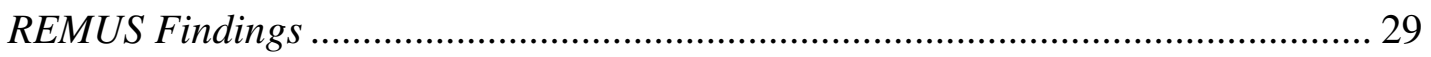

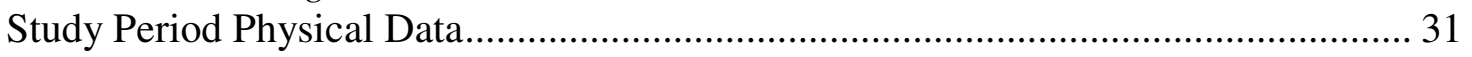

Study Period Biomass ........................................................................................ 32

Study Period Community Structure ……………………......................................... 33

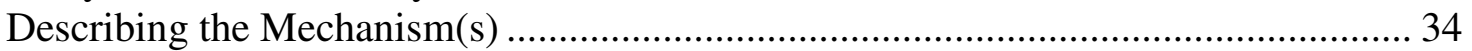

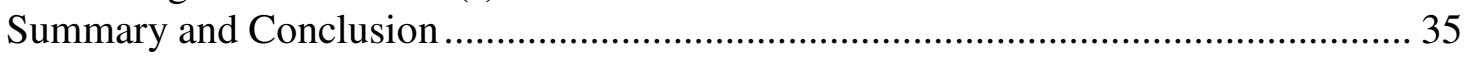

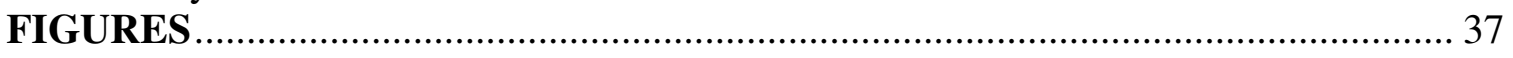

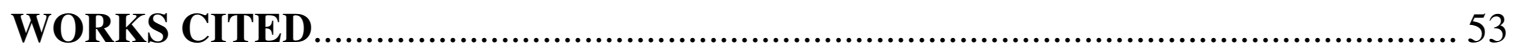




\section{LIST OF FIGURES}

Figure 1. A) Location of NOAA buoy 46062 (4606235.101N, 121.010W) and NOAA temperature gauge 9412110 (35.169N, 120.754W) relative to the San Luis Obispo Bay and the California coast. B) Transponder location. Transponders B and C were deployed from the research facility pier and located at $35.1728 \mathrm{~N} 120.7411 \mathrm{~W}$ and $35.1697 \mathrm{~N} 120.7407 \mathrm{~W}$. Transponders D, E, F, G, and A were fixed via mooring and deployed at $35.1677 \mathrm{~N} 120.7231 \mathrm{~W}, 35.1519 \mathrm{~N} 120.7263 \mathrm{~W}, 35.1423 \mathrm{~N} 120.7388 \mathrm{~W}$, $35.1333 \mathrm{~N} 120.7545 \mathrm{~W}$, and $35.1237 \mathrm{~N} 120.7697 \mathrm{~W}$.

Figure 2. Oceansat-1 OCM image taken on 1/21/2004 showing nearshore and offshore sampling points for satellite imagery analysis. . Point A (nearshore) was located at the end of the Cal Poly Center for Coastal Marine Sciences pier facility $(35.1697 \mathrm{~N}$ $120.7407 \mathrm{~W}$ ), while point B (offshore) was located at NOAA buoy $46062(35.101 \mathrm{~N}$, 121.010W). 38

Figure 3. Deployment of REMUS 100 AUV during June 2004. Instrumentation includes

a CTD and a fluorometer/backscatter sensor. Total vehicle length was $3.0 \mathrm{~m}$......... 39

Figure 4. A) Map of the REMUS mission track used in this study. The transponder locations are shown in red. Missions were J-shaped in order for the vehicle to safely clear the tip of the break-wall (BW on figure) located in the northwest corner of the bay. B) REMUS mission depth map showing its surface position (flat line) as it moved offshore followed by its undulating return (jagged line).

Figure 5. Mooring design allowing for easy replacement of transponders without disturbance of mooring. Deployed transponders were positioned at approximately one half the depth of the water column, which was the mid-point of the REMUS operations to optimize communication and navigation.

Figure 6. Physical data reported from 1/1/2004 to 6/30/2004. A) Sea surface temperature plot from 1/1/2004 through 6/30/2004 demonstrating low stable values during the winter and elevated fluctuating values during the summer. (Nearshore) measurements (blue) were reported from NOAA temperature gauge 9412110 while offshore measurements (pink) were reported from NOAA buoy 46062 (offshore). B) Difference plot demonstrating increases in SST fluctuation as summer approached. Temperature is reported as (nearshore-offshore). C) Wind data showing directional dominance from between 300 and 350 degrees. Data also demonstrates elongated periods between shifts reported during the late spring and summer. D) Wind speed data showing relaxation periods corresponding to shifts in wind direction.

Figure 7. A through F) Oceansat-1 OCM images taken from 3/21/2004 to 4/6/2004 showing chlorophyll a accumulation. G) Graphical extrapolation of chlorophyll a concentration vs. time. Red circle shows chlorophyll a concentrations concurrent to images A through F. (Nearshore) measurements (blue) were reported from NOAA temperature gauge 9412110 while (offshore) measurements (pink) were reported from NOAA buoy 46062 .

Figure 8. Biomass estimates reported from 1/1/2004 to 6/22/2004. A) Satellite chlorophyll a concentration. (Nearshore) measurements (blue) were reported from NOAA temperature gauge 9412110 while (offshore) measurements (pink) were reported from NOAA buoy 46062. B) Satellite chlorophyll a difference plot. 
Temperature is reported as (nearshore-offshore). C) HPLC chlorophyll a concentration. D) Total phytoplankton abundance from microscopic identification.

Figure 9. Community structure from 1/1/2004 to 6/22/2004 reported as normalized percent composition. A) High Performance Liquid Chromatography (HPLC), percent composition of fucoxanthanin (Fuc), diadinoxanthanin (Diad), diatoxanthanin (Diato), and peridinin (Perid). (B). HPLC percent composition of alloxanthin (Allo), hexanoyloxyfucoxanthin (Hex), prasinoxanthin (Pras), and zeaxanthin (Zeax). C). HPLC percent composition of butanoyloxyfucoxanthin (Hex), neoxanthin (Neo), violaxanthin (Viol), and lutenin (Lut). D) Percent composition of diatoms and dinoflagellates from microscopic identification. Shaded gray area shows REMUS deployment period 6/4/2004 to 6/16/2004. 45

Figure 10. REMUS data reported on 6/4/2004 showing 3-dimensional distribution of A) Temperature, B) Salinity, and C) Chlorophyll a. 46

Figure 11. REMUS data reported during our study period showing leg 5 and 6 average values. A) Chlorophyll a, B) Temperature, C) Salinity, and D) Density................. 47

Figure 12. Physical data reported during our study period from 6/1/2004 to 6/22/2004 A) SST, nearshore (blue) reported from NOAA temperature gauge 9412110 , offshore (pink) reported from NOAA buoy 46062. B) SST difference plot (nearshoreoffshore), C) Wind direction form NOAA buoy 46062, and D) Wind speed from NOAA buoy 46062.

Figure 13. Biological data reported during our study period from 6/1/2004 to 6/22/2004 I) Satellite chlorophyll a concentration, J) Satellite chlorophyll a difference plot (nearshore-offshore), K), HPLC chlorophyll a concentration, and L) Microscopy total phytoplankton.

Figure 14. Community structure during our study period from 6/1/2004 to 6/22/2004 reported as normalized percent composition. A) High Performance Liquid Chromatography (HPLC), percent composition of fucoxanthanin (Fuc), diadinoxanthanin (Diad), diatoxanthanin (Diato), and peridinin (Perid). (B). HPLC percent composition of alloxanthin (Allo), hexanoyloxyfucoxanthin (Hex), prasinoxanthin (Pras), and zeaxanthin (Zeax). C). HPLC percent composition of butanoyloxyfucoxanthin (But), neoxanthin (Neo), violaxanthin (Viol), and lutenin (Lut). D) Percent composition of diatoms and dinoflagellates from microscopic identification.

Figure 15. REMUS Temperature vs. Salinity plots. A) Data taken from the surface 3M of the inner harbor return. B) Data taken from bottom 3M of the inner harbor return. Data shows distinct upwelling event on 6/10/2004 (yellow), followed by poleward water replacement on 6/14/2004 and 6/16/2004 (turquoise, red).

Figure 16. Diagram of water movement based on described mechanism. Reported dates determined by REMUS salinity vs. temperature data. Wind direction shown in yellow and water movement shown in red. A) Strong north-west wind forcing and retention B) Declining wind forcing and replacement by cool saline upwelled waters C) Weak wind forcing and replacement by warm fresh poleward movement. 


\section{INTRODUCTION}

\section{Phytoplankton}

Phytoplankton play a key role in the marine ecology of San Luis Obispo Bay. These microscopic, single-celled organisms are commonly found in nearshore coastal areas, within the upper 50m of the water column (Cloern 1996). The name "phytoplankton" consists of two Greek words meaning "plant" (phyto) and "wanderer" (plankton). There are two major groups of phytoplankton, "diatoms," and "flagellates," including "dinoflagellates." Diatoms generally have no means of active locomotion, whereas the flagellates and dinoflagellates can migrate vertically in the water column in response to gradients in factors such as light and nutrients (Ryan et al. 2008). Motility of dinoflagellates can provide competitive advantage over non-motile species under stratified conditions (Ryan et al. 2005). Both groups of phytoplankton are influenced by oceanic currents for transport to areas that are suitable for their survival and growth. Because of this, physical processes play a significant role in determining the distribution, concentration and species composition (Langolis and Smith 2000).

Phytoplankton are capable of rapid cell division and can produce millions of cells per liter of seawater in relatively short periods of time. Growth rates of phytoplankton vary depending on factors such as nutrient availability, irradiance levels, and day length (Gilstad and Sakshaug 1990). Diatoms are generally faster growing than dinoflagellates. Durbin (1974) reported that the maximum growth rate of Thalassiosira grown at 48 different combinations of day length, light intensity, and temperature, in terms of cell division, was $1.8 \mathrm{~d}^{-1}$ or nearly twice a day. The dinoflagellate Gymnodiniun sp., one of the popular causative organisms of the red tides occurring in the eastern Pacific Ocean, was 
shown to have a maximum growth rate in terms of cell division of $.95 \mathrm{~d}^{-1}$ or nearly once a day (Iizuka and Mine 1983). Because of this ability, phytoplankton are the first link in nearly all marine food chains, providing food for a tremendous variety of organisms, including zooplankton, bivalve molluscan shellfish, and small fish (Langolis and Smith 2000). These animals, in turn, provide food for animals higher up in the food chain such as crabs, fish, birds, marine mammals and ultimately humans.

Phytoplankton are commonly recognized for their role in the development of harmful algal blooms and "red tides." The term "red tide" is misleading, because phytoplankton blooms are frequently other colors, such as brown, green, and yellow, and are in any case not a tidal phenomenon (Langolis and Smith 2000). "Red tides" are formed by dense accumulations of certain phytoplankton making the ocean appear reddish (Ryan et al. 2005). Of the more than 5000 known species of marine phytoplankton, approximately 40 species have been shown to produce marine biotoxins (Langolis and Smith 2000). Blooms of phytoplankton containing biotoxins are of extreme significance as they are responsible for harmful algal blooms, poisoning marine life and negatively impact coastal fisheries and human health (Ryan et al. 2005).

\section{Distribution}

Local oceanographic conditions appear to influence the distribution of phytoplankton. Tont $(1976,1981)$ showed diatom abundances to be associated with coastal upwelling, with several blooms of 5-6 weeks duration during summer months. On the other hand, shifts in phytoplankton species dominance can occur over alongshore distances of less than $100 \mathrm{~km}$ and change in a matter of days. Abbott et al. (1990) found that species composition along a drifter track changed over time scales of 2-3 days. Ryan 
et al. (2008) demonstrated blooms persisting for over a month but emphasized their patchiness and illustrated small-scale physical processes influencing bloom distributions. In addition to physical processes such as eddies, currents, and convergence zones, Ryan et al. (2005) suggests that species specific attributes such as flagellar motility or buoyancy is also an important component in phytoplankton distribution.

Phytoplankton distribution is also greatly influenced by physical processes such as currents. The California current is a Pacific Ocean Current located off of the west coast of North America. The core of this current is normally more than $100 \mathrm{~km}$ seaward while filaments can extend up to 1000km offshore (Miller et al. 1999; Collins et al. 2003). The California Current begins off Southern British Columbia and deposits biologically productive waters as it moves southward until its termination off of southern Baja California (Miller et al. 1999). Additionally, extensive upwelling of cold nutrient rich, sub-surface waters occurs, caused by the prevailing northwesterly winds and Ekman forcing (Collins et. al 2003). This process adds to the biological productivity and further cools the already cool California Current (Miller et. al 1999).

During the winter months, strong southwesterly winds begin to cause a northward coastal countercurrent running inshore of the California Current. The Davidson Current is typically between 40 and 50 miles wide and brings warm waters from the south northward (Schwarzlose et al. 1972). Minimum speeds in the Davidson Current during the winter have been reported at approximately 0.6 knots, indicating that it is very strong relative to the offshore California Current (Schwarzlose et al. 1972). In the spring, primarily in April but occasionally in May, the winds off California turn southward again and the northward flow of the Davidson Current ceases (Schwarzlose et al. 1972). 
Upwelling is another process that greatly affects both phytoplankton distribution California's coast. Upwelling is a phenomenon where cold nutrient-rich water is driven to the surface due to wind, the angle of the coastline, and the Earth's rotation (Collins et. al 2003). Along the west coast of the U.S., winds blowing from the north tend to drive ocean currents to the right of the wind direction and thus push surface waters offshore. As surface waters are pushed offshore, water is drawn from below to replace them. This cold deep nutrient rich water is brought to the surface during the spring months when the winds blow out of the northwest (Parrish and Tegner 2001). Wind velocities and upwelling are variable along the central California coast but tend to be at a maximum in the spring to early summer in the region between Point Conception $\left(34.5^{\circ} \mathrm{N}\right)$ and the Oregon border $\left(42^{\circ} \mathrm{N}\right)$. (Parrish and Tegner 2001).

Upwelling not only provides nutrient rich water from the deep but also physically concentrates phytoplankton near the surface (Langolis and Smith 2000). Upwelling and horizontal flows can also concentrate phytoplankton near the surface at convergence zones (Ryan et. al 2005). Positively buoyant diatoms can form spectacular accumulations in convergence zones in the equatorial Pacific (Yoder et al. 1994). This concentration along with increased nutrients initially provides a competitive edge for the faster growing diatoms during upwelling events. Conversely, a stratified water mass consisting of a layer of warmer surface water and a deeper layer of colder, nutrient-rich water can form following upwelling (Langolis and Smith 2000). These conditions favor the development of dinoflagellate blooms because of their ability to actively swim to the surface to photosynthesize during the day and migrate to deeper areas at night to exploit nutrients (Langolis and Smith 2000). Blasco (1978) showed that Ceratium furca 
possessed the ability to migrate against vertical currents off Baja California. The strong swimming ability of $C$. furca combined with its high ratio of swimming to sinking further demonstrates the ability of dynoflagellates to exploit such stratified nutrient conditions (Smayda, 2002). Additionally the flagellar motility of dinoflagellates allows dense surface aggregations at convergence zones where downwelling is present due to their ability to actively swim upward against downward flows (Ryan et al. 2005).

\section{San Luis Obispo Bay Dynamics}

Phytoplankton composition, advection, and growth can be affected by a variety of physiological factors. Of theses factors, coastal topography and specifically the impact of local hydrography may perhaps be one of the most important. Bays, harbors, and other topographical anomalies affect in the process of phytoplankton growth and in turn, also effect advection (Wing et al. 1998). San Luis Obispo Bay exhibits a unique local hydrography that strongly influences phytoplankton dynamics.

Local coastline orientation and topography have been shown to strongly affect the direction and intensity of coastal wind (Zemba and Friehe 1987). Enhanced upwelling has been seen at Cape Mendocino (Largier et al. 1993), Point Arena (Kelly 1985), Point Año Nuevo (Rosenfeld et al. 1994) and Point Sur (Traganza et al. 1981). Suppressed upwelling has been observed both upwind of capes (e.g., north of Cape Mendocino, Largier et al. 1993) and downwind of capes (e.g., south of Point Ano Nuevo, in Northern Monterey Bay (Rosenfeld et al. 1994.). Further, if there is a substantial area of weak winds downstream of a cape (i.e., in the lee of a cape), an upwelling shadow can be found (Graham et al. 1992). Moreover, in the lee of some capes, circulation patterns occur that are retentive (Graham et al. 1992). 
One of the most important aspects of San Luis Obispo Bay's ability to affect phytoplankton growth and advection is the presence of a lee and proposed upwelling shadow. A lee is created as the prevailing winds, waves or currents are prevented from directly disturbing a body of water (Siler et al. 1964). This prevention allows for prolonged retention and allows the shallow sunlit waters ample time for phytoplankton growth with little disturbance. In addition an upwelling shadow inhibits the effect of nearshore upwelling thus reducing mixing (Graham et al. 1992). Reduction in upwelling and unperturbed conditions may allow for the formation of phytoplankton bloom incubation areas (Ryan et al. 2005).

Phytoplankton bloom incubation areas are evident in other coastal upwelling systems including Monterey Bay, California (Ryan et al., 2008), Libson Bay, Portugal (Moita et al., 2006), Paracas Bay, Peru (Kahru et al., 2004), and St. Helena Bay, South Africa (Pitcher and Nelson, 2006; Fawcett et al., 2007). Ryan et al. (2008) reported that Monterey Bay California experiences intense and frequent dynoflagellate blooms. These blooms contain surface chlorophyll exceeding 500 $\mathrm{gg}^{-1}$ and occupy $\sim 5$ to $80 \mathrm{~km}^{2}$ (Ryan et al. 2008). These blooms are most common from August through November and can persist for longer than one month (Ryan et al. 2008).

Phytoplankton bloom incubation areas are periodically affected by events resulting in flushing (Ryan et al. 2005). In Monterey Bay, California one such flushing event resulted from the intrusion of a filament of the California Current during wind relaxation (Ryan et al. 2005). Ryan et al. (2005) reported that in a five-day period, unperturbed conditions with abundant phytoplankton in the bay were completely displaced by an intrusion of waters that were relatively chlorophyll-poor and warm. 
Local hydrography along with preliminary findings suggests that San Luis Obispo Bay California may be one such phytoplankton bloom incubator. The presence of a lee and proposed upwelling shadow are believed to greatly influence phytoplankton dynamics by increasing retention (Graham et al. 1992). This study examines phytoplankton dynamics in San Luis Obispo Bay including accumulation, advection, and composition using all the primary techniques of ocean monitoring encompassed in the coastal module of the Global Ocean Observing System (UNESCO 2003). These techniques included remote sensing, autonomous sensing, discrete sampling and laboratory analysis. By incorporating these techniques we plan to monitor the effect of the bay's local hydrography on phytoplankton dynamics. Through multispatial multidisciplinary techniques we aim to describe the cyclic phytoplankton patterns of growth and advection as well as identify the physical mechanism(s) responsible for these patterns. 


\section{METHODS}

Physical Data Sampling

In order to explore the mechanisms governing phytoplankton dynamics in San Luis Obispo Bay, CA, we examined a variety of physical and biological data. Wind data was catalogued from 01/01/2004 to $06 / 30 / 2004$ by instruments located on NOAA buoy 46062; 35.101N, 121.010W (Fig. 1A). The anemometer on this buoy was located $5 \mathrm{~m}$ above sea level measuring wind direction and velocity at 10 -minute intervals.

Next, we examined sea surface temperature (SST) data reported from both nearshore and offshore stations. SST data from NOAA station 9412110; (nearshore), along with SST data from NOAA buoy 46062; (offshore), was recorded and catalogued from $01 / 01 / 2004$ to $06 / 30 / 2004$. The benchmark for NOAA gauge 9412110 is located on the harbor district grounds $35.177 \mathrm{~N}, 120.760 \mathrm{~W}$ at the entrance to Diablo Nuclear power plant along Avila road; however, the actual placement of the instrument is $35.169 \mathrm{~N}$, $120.754 \mathrm{~W}$, located in the icehouse on the pier. The location of NOAA buoy 46062 was $35.101 \mathrm{~N}, 121.010 \mathrm{~W}$ resulting in a direct linear distance of $24.48 \mathrm{~km}$ between the two instruments. NOAA buoy 46062 was disestablished on November 21, 2004 (Fig. 1A \& 1B).

\section{Biological Data Sampling}

Chlorophyll a concentration was obtained from the Oceansat-1 OCM (ocean color monitor) satellite with images provided by the Sea Space Corporation. Images were catalogued from 01/01/2004 through 06/22/2004 removing images with insufficient data due to poor atmospheric conditions. Suitable images were analyzed and chlorophyll a 
concentrations were extrapolated at designated nearshore and offshore points. Point A (nearshore) was located at the end of the Cal Poly marine sciences research facility pier, while point B (offshore) was located at NOAA buoy 46062 (Fig 2).

Photosynthetic phytoplankton pigments can be used as chemotaxonomical markers for investigating the composition of phytoplankton communities (Suzuki et al., 1995; Andersen et al., 1996; Suzuki et al., 1997). More recently, Andersen et al. (1996) made an attempt to compare the taxonomic composition based on phytoplankton pigment signatures as measured by HPLC, with direct electron microscopic taxonomic identifications. As a result, they found that electron microscopic observations and pigment data were reasonably similar in taxonomic composition, at least at the class level. Therefore, while microscopic analysis requires a high level of taxonomic skill, is often time consuming, and can be variable among personnel, high performance liquid chromatography (HPLC) pigment data can provide a good first approximation of the taxonomic composition of phytoplankton (Millie et al. 1993). This study aims to utilize both HPLC analysis of pigments as well as microscope observations to determine both abundance and species composition.

In order to quantify phytoplankton pigments, weekly surface seawater samples were collected for six months from 01/01/2004 to 06/22/2004 via surface sampling container from the California Polytechnic State University marine sciences pier. 1000mL of sample was filtered using Whatman $25 \mathrm{~mm}$ GF/F glass fiber filters and vacuum pump at $300 \mathrm{mmHg}$ and were performed in triplicate. Filters were stored in $20 \mu \mathrm{L}$ cryovac tubules and placed on ice in an insulated container for transport. Samples were 
transported and frozen within an hour of sampling $\left(-40^{\circ} \mathrm{C}\right)$ and stored for later HPLC analysis.

Sampling for microscopy consisted of the collection of weekly surface seawater samples from 01/01/2004 to 06/22/2004 via surface sampling container from the California Polytechnic State University marine sciences pier. One liter of seawater was filtered using a $20 \mu \mathrm{m}$ hand held screen filter. The filtered samples were then collected from the screen filter into glass collection jars by rinsing the filter with $25 \mathrm{~mL}$ of filtered seawater. $0.025 \mathrm{~mL}$ of $100 \%$ acetic acid was then added and samples were stored for later analysis.

Phytoplankton samples were settled in $1 \mathrm{~mL}$ settling chambers and quantified. Quantification was performed in triplicate and averages were determined. Samples were identified to the species level (where possible) using an Olympus inverted microscope. Microscopy identification was performed in triplicate and species averages were calculated.

\section{Autonomous sampling}

Upon identification and quantification using point specific or surface level sampling techniques, we employed a sampling platform that would identify the process over a multi-dimensional field. The Autonomous Underwater Vehicle (AUV), used during the study was a Remote Environmental Monitoring UnitS (REMUS)100, constructed by Hydroid Inc. The vehicle has a standard length of $160 \mathrm{~cm}$, diameter of 19 $\mathrm{cm}$, and weighs $37 \mathrm{~kg}$. The REMUS is propeller-driven vehicle powered by four $26 \mathrm{~V} / 10$ Ah lithium-ion batteries that enable ranges of over $80 \mathrm{~km}$ at speeds of 3 knots. The midsection houses the compass, heading sensors, yaw rate sensor, control computer and 
batteries. The forward compartment houses the vehicle's Acoustic Doppler Current Profiler (ADCP), which consists of four upward and four downward looking transponder beams that are used to measure current velocity and direction. The downward looking array is also used as an altimeter, allowing for bottom tracking/mapping and fixed altitude flight. Forward of the ADCP is the backscatter/fluorometer, a downwelling irradiance sensor and an upwelling radiance sensor (Fig. 3) (Moline et al. 2007).

The REMUS has three modes of navigation however only two were used during this study. The primary type of navigation used long base-line (LBL), employs a fourchannel hydrophone to interrogate an array of digital acoustic transponders deployed in the area of study. The latitude and longitude of each of the transponders is preprogrammed into the REMUS mission file. LBL navigation is based on the principles of triangulation with the vehicle calculating its position by computing its range to the acoustic transponders. The maximum range of acoustic fixation is $2.5 \mathrm{~km}$ thus requiring transponder placement at distances usually less than $2 \mathrm{~km}$. During periods between triangulated fixes or when acoustic fixes are not available, the vehicle navigates in dead reckoning mode, relying on compass heading and last known position to navigate to its next programmed waypoint (Moline et al. 2007).

Prior to vehicle deployment, placement of a series of transponders was required in order for the REMUS 100 to accurately triangulate its position. Transponders were placed at distances of approximately $2 \mathrm{~km}$ apart requiring a total of seven in order to reach an offshore distance of $5 \mathrm{~km}$. Of the seven required transponders, two were deployed on a daily basis directly from the research facility pier, while five were deployed on a semi-permanent basis. The transponders deployed from the research 
facility pier were located at $35.1728 \mathrm{~N} 120.7411 \mathrm{~W}$ and $35.1697 \mathrm{~N} 120.7407 \mathrm{~W}$.

Transponders fixed via mooring were deployed at $35.1677 \mathrm{~N} 120.7231 \mathrm{~W}, 35.1519 \mathrm{~N}$

$120.7263 \mathrm{~W}, 35.1423 \mathrm{~N} 120.7388 \mathrm{~W}, 35.1333 \mathrm{~N} 120.7545 \mathrm{~W}$, and $35.1237 \mathrm{~N} 120.7697 \mathrm{~W}$

(Figs. 1B \& 4A). Water depth of moorings ranged from $10 \mathrm{~m}$ to $30 \mathrm{~m}$ (Fig. 4B).

The semi-permanent moorings were designed to anchor the transponder while

allowing for removal or replacement of the transponder without complete removal of the mooring itself. This was necessary because the battery life of the transponders was limited to approximately two weeks. Moorings were constructed using a 50lb. concrete and steel anchor attached to three feet 3/8-inch galvanized chain with a galvanized shackle. The chain was then attached to 1/2-inch polypropylene rope with a 3/8-inch galvanized eyelet woven into the rope. The buoy used was a standard 14-inch crab float, which was attached to the end by splicing the rope back into itself. Transponders were placed at half the water column depth and were attached using a 1/4-inch stainless shackle attached to two feet of 3/8-inch galvanized chain that had been woven into the polypropylene rope (Fig. 5).

AUV missions were performed on 05/18/2004, 06/04/2004, 06/07/2004, 06/10/2004, 06/14/2004, and 06/16/2004. Of these six missions, five were designed to gather data while the first was designed to be an inaugural run. By running five data gathering missions over a period of twelve days, the intention was to capture at least one cycle of accumulation and advection of phytoplankton in the area. The vehicle was outfitted with a CTD, chlorophyll fluorometer and backscatter sensor in order to spatially sample the physical and biological dynamics. 
The inaugural mission on 5/18/2004 was a preliminary run designed to get the REMUS 100 in the water and ensure that all systems were properly functioning. This mission consisted of a box-like run paralleling the coastline with a continuous dive depth of $4 \mathrm{~m}$ from the surface. The REMUS 100 was programmed to travel approximately 1.5 $\mathrm{km}$ from the deployment site at the Cal Poly research facility before turning to the south for a short offshore run, $0.25 \mathrm{~km}$, and then finally returning back to the deployment site. The run was designed to be short and nearshore for easy vehicle retrieval if any problems arose.

Subsequent missions were designed to extend from the point of deployment to a distance of approximately $5 \mathrm{~km}$ offshore. Extending to this distance allowed for the REMUS 100 to pass through the entire lee and upwelling shadow and reach a sufficient distance to visualize the break or edge of the phytoplankton plume. Missions were Jshaped in order to have the REMUS 100 safely clear the breakwater located in the northwestern corner of the bay (Fig. 5A). Each mission consisted of offshore sampling at a depth of $1 \mathrm{~m}$ followed by returning onshore undulations from the surface to within $4 \mathrm{~m}$ of the bottom. The offshore sampling allowed for a constant measurement near the surface while the onshore return enabled a depth stratification component (Fig 4B). 


\section{RESULTS and DISCUSSION}

A central question of our project was to explain the apparent paradox of high phytoplankton biomass during upwelling conditions (Kudela et al. 2008). Although upwelling provides nutrients, it also results in increased export of plankton from the shelf (Largier et al., 2004). As a result, two varying mechanisms were explored in order to develop a conceptual model for phytoplankton dynamics in San Luis Obispo Bay. The first proposed mechanism suggests that the bay experiences upwelling conditions similar to many areas of the California coast where cool, nutrient rich water is deposited in the bay during equatorial wind forcing. When these winds relax, water in the bay is replaced by warmer nutrient poor filaments of the California Current System. Ryan et al. (2005) describes a similar condition in his description of "phytoplankton bloom incubators."

The second mechanism explored was based on the hypothesis that San Luis Obispo Bay experiences retention and prolonged periods of warming due to insolation during periods of equatorial wind stress. In this model, it is suggested that when these winds relax, the water in the bay is replaced by cooler water from nearby upwelled regions. The second hypothesis appears to be supported by the local topography and unique hydrography of the bay. It is believed that the conditions created are similar to those described by Graham et al. (1992), Wing et al. (1998), and Marin et al. (2003) suggesting the presence of an upwelling shadow. Initial hypotheses suggest the later of

the two mechannisms to be most accurate for San Luis Obispo Bay, however subsequent findings demonstrate that accurate modeling may include elements from both. 
A valid conceptual model for phytoplankton dynamics in San Luis Obispo Bay consists of two related but distinct predictions. First; that prolonged periods of insolation and retention will lead to phytoplankton accumulation. Second; periodic advection events will lead to phytoplankton dispersal. Both predictions are shown to occur in San Luis Obispo Bay and are demonstrated by the cyclical patterns in both physical and biological data. This study attempted to create a model that accurately describes these patterns over seasonal and single cycle scales as well as describes the mechanism(s) driving the process.

Seasonal Physical Data

Wind

Wind direction from NOAA buoy 46062 demonstrated dominance from between 300 and 350 compass degrees, corresponding to winds blowing from the northwest. Distinct directional shifts could be observed, but did not appear to remain constant from any other direction than from the northwest. During the winter these shifts occurred often (4.5 days/shift) while frequency decreased to (16 days/ shift) by late spring (Fig. 6C). Chavez et al. (2000) reports similar findings off of Monterey showing that alongshore daily wind stresses are predominantly equatorial with reversals in winter. Brink and Cowles (1991) suggest that during this time winds become more variable as storms frequently reverse the wind direction. The transition between winter storms, with strongly fluctuating poleward winds to persistently equatorial winds appears to occur rapidly. Direction during the spring and summer reported dominant equatorial stress with only occasional shifts in direction corresponding to relaxation. Bakun and Nelson (1977) suggest similar findings showing that in spring and summer, there are relaxations in 
equatorial winds with periods of several days. Strub and James (1987) also indicated that wind direction along the California coast often undergoes seasonal changes.

Examination of wind velocity revealed a direct relationship with direction.

Equatorial forces reported higher velocities than from any other direction. In addition, as direction shifted poleward, wind speed decreased or in some cases even ceased. This association reveals the well-described process of wind relaxation common to the California coast (Bakun and Nelson 1977). Winds characteristic during periods of relaxation have been identified as periods when equatorial velocities are less than $3 \mathrm{~ms}^{-1}$, while velocities typical of upwelling exceed $5 \mathrm{~ms}^{-1}$ (Largier et al. 1993). In contrast, poleward wind velocities greater than $5 \mathrm{~ms}^{-1}$ identify periods of downwelling (Largier et al. 1993). All three scales of wind forcing were observed during our study (Fig. 6D).

\section{SST}

Sea surface temperatures (SSTs) in San Luis Obispo Bay during the winter were relatively low and stable, in contrast, spring and summer had elevated cyclical patterns. Cycles typically lasted approximately 5 weeks (36.2 days). SST peaks reported during the summer reported elevated values reaching $16.6^{\circ} \mathrm{C}$ and fluctuations of $6.5^{\circ} \mathrm{C}$ (Fig. 6A). Temperature trends were similar along other areas of the California coast. Breaker (1986), and Brink and Cowles (1991) suggest that spring transition to coastal upwelling occurs on average, between mid-March and mid-April and can bring SST decreases as much as $5{ }^{\circ} \mathrm{C}$ within a few days. In Monterey Bay the average annual cycle of sea surface temperature also shows spring as the cooler time of the year in phase with the local wind field (Chavez et al. 2000). 
In addition to individual SST measurements, SST relativity between values recorded from Port SLO (nearshore) and NOAA buoy 46062 (offshore) were also examined. Results demonstrate that offshore values are relatively higher than nearshore during the winter. Measurements during the spring and summer demonstrate significant increases in fluctuation along with nearshore reporting higher values during this time (Fig. 6B).

Both advection as well as local surface heat flux may have been responsible for the observed increases in SST during the summer. In terms of insolation, Graham and Largier (1997) calculated that in Monterey Bay, the thermal change due to heating was $0.5^{\circ} \mathrm{C}_{\text {a day }^{-1}}$. At this rate, residence times of 12-13 days may account for the reported changes in temperature reported during our study.

Advection also appeared to demonstrate an effect on water temperature in the bay and can be described by surface and subsurface events. At the surface level; periods of wind relaxation report elevations in SST values. These elevations are reported both nearshore and offshore and demonstrate a temporal lag that is consistent with an intrusion of warm offshore surface waters. This suggests that during relaxation and reduced equatorward forcing, warm offshore surface waters are allowed to displace the relatively cool waters of the bay. Frictional force at the surface creates a buildup of equatorward waters during prolonged periods of forcing. Once this forcing is reduced or relaxed this build up is allowed to return poleward. Ryan et al. (2005) reports a similar warm water intrusion into Monterey Bay, during which the internal waters of the bay were displaced by a filament of the California Current System during relaxation. At the subsurface level advection appears to be due to upwelling and is most prevalent post relaxation when 
strong equatorial forcing resumes. During this time both nearshore and offshore stations report declines in SST suggesting displacement by cool waters from the deep (Fig 6A). Findings are supported by the ERD 2004 coastal upwelling indices revelaing the presence of upwelling conditions during these times.

\section{Wind and SST Relationship}

Wind stress is commonly recognized as the most important driving force for coastal upwelling (Penven et al. 2002). In general, coastal upwelling occurs along eastern ocean margins when equatorial winds act in combination with the Coriolis force to move surface waters offshore, drawing deeper water to the surface (Chavez et al. 2000). This upwelled water typically occurs as a cool band along the coast that is separated from warmer offshore waters by a series of variable fronts, plumes and eddies (Chavez et al. 2000).

In San Luis Obispo Bay, the local topography appears to have an impact on wind stress, and thus a direct effect on SST. During upwelling season when winds are predominantly equatorial, wind stress is inhibited creating conditions that shelter the majority of the bay. This results in elevations in SST during conditions that typically result in decreases (Graham and Largier 1997). Marin et al. (2001) suggests that in Mejillones Bay Chile, higher temperatures found inside the bay, even during active upwelling, agree with the presence of an upwelling shadow. The presence of such a shadow in San Luis Obispo Bay has been proposed and may explain both elevated nearshore SST values as well as increasing SST during periods typical of upwelling. At any rate, conditions in the bay demonstrate some degree of retention as described by elevated nearshore temperatures during upwelling conditions. Graham et al. (1992); 
Graham and Largier, (1997) demonstrated that temperature is strongly influenced in coastal regions where mixing is infrequent creating conditions that are retentive. In addition, upwelling shadows report enhanced residency times which have been proposed as playing a disproportionately role in the ecology of coastal areas (Graham et al. 1992).

\section{Seasonal Biomass}

Satellite Imagery

Subsequent to examination of the physical conditions common to San Luis Obispo Bay, we attempted to explore the biological conditions associated with the physical dynamics. Satellite imagery was examined and provided the first record of biological support for our hypothesis of cyclical patterns of phytoplankton accumulation and advection. Satellite images demonstrate distinct cycles of chlorophyll a concentration (Fig. 7A through 7G). Cycle duration was relatively uniform with periods of approximately 5 weeks (35.2 days). Amplitude of cycles showed elevated chlorophyll a values during the winter and early spring while values declined as summer approached (Fig. 8A). Poor resolution or missing data due to marine layer conditions and cloud cover prevented accurate cycle period estimations of biomass.

Data demonstrating elevated nearshore chlorophyll a concentrations in the winter and spring were not reported by other sampling methods suggesting possible inherent errors in the applied satellite imagery analysis techniques. First; point specific analysis fails to recognize chlorophyll distribution stretched over large surface areas. Second; satellite imagery presents data in two a dimensional field only and cannot account for the depth component. Both discrepancies fail to account for chlorophyll concentration variations in distance and depth. Michaelsen et al. (1988) found that annual cycles in 
upper layer chlorophyll show winter maxima and summer minima, but the "total" (i.e., in the entire water-column) peaks in early summer, suggesting that depth is a vital component in recording phytoplankton concentration.

Pigmentation, Identification and Quantification

The ability to accurately estimate phytoplankton biomass by the photosynthetic pigment chlorophyll a, which is found in all phytoplankton cells (Newton 2002), enabled the estimation of biomass in San Luis Obispo Bay using both direct microscopy counting techniques as well as HPLC derived chlorophyll a concentrations.

HPLC Chlorophyll a (chl a), concentrations revealed cyclical patterns throughout our study. Cycle duration was fairly uniform with an average period of (27.7 days/cycle). Peak concentrations of chl a were reported during the late spring and summer reporting similar patterns and concentrations to other phytoplankton communities along the California coast (Tont 1989) (Ryan et al. 2005). Typical patterns of California coastal phytoplankton dynamics consist of increases in phytoplankton abundance during spring months, when the wind blowing out of the northwest brings nutrient rich upwelling to the coast (Parrish and Tegner 2001). Although peak chl a values demonstrated low variation $\left(\mathrm{STDEV}=1.88 \mathrm{mg} \mathrm{m}^{-3}\right)$ amplitude increased as summer approached (Fig 8C).

Although often labor intensive and prone to error due to observational variance, microscopy enables accurate quantification as well as identification to the species level. Phytoplankton biomass as described by microscopy during the winter remained fairly consistent and relatively low. Two prominent peaks demonstrating concentration increases by approximately nine orders magnitude developed during the spring and early summer reporting an average cycle period of (37.5 days/cycle)(Fig. 8D).The first peak in 
phytoplankton concentration appeared at the end of March; just around the time that typical upwelling season begins to reach the California coast (Michaelsen et al. 1988). The presence of peaks arriving at this time suggests that upwelling is a vital component of phytoplankton accumulation (Michaelsen et al. 1988).

Upwelling is perhaps the single most important seasonal change in terms of largescale impact and biomass accumulation (Walsh 1991). Biomass in San Luis Obispo Bay was low during the winter and increased during the spring and summer. This strong association with the upwelling season suggests a clear physical-biological coupling in the time series data. Patterns are consistent with arrival of upwelling and the conditions that it brings (Lassiter et al. 2005; Chavez et al. 2000). Of the reported data, satellite imagery was the only set that did not follow this pattern. This can be explained by inherent errors in satellite imagery analysis techniques.

The apparent reoccurring pattern of phytoplankton blooms in San Luis Obispo Bay suggests physical conditions supporting such cycles. Blooms are events of rapid production and accumulation of phytoplankton biomass that are usually responses to changing physical forcing originating in the coastal ocean (Cloern 1996). In San Luis Obispo Bay, these cycles demonstrate strong coupling with SST, and in turn wind forcing. These physical events have different timescales of variability, so algal blooms can be short-term episodic events, recurrent seasonal phenomena, or rare events associated with exceptional climatic or hydrologic conditions (Cloern 1996). 


\section{Seasonal Community Structure}

Pigmentation, Identification and Quantification

Subsequent to biomass quantification, we examined the composition of the phytoplankton community using HPLC, which allows identification of phytoplankton composition with great accuracy. Marker pigments unique to specific phytoplankton groups provide an insight into community structure (Andersen et al., 1996).

Levels of total accessory pigment concentration demonstrated cyclical patterns that strongly mirrored those of chlorophyll a (Fig. 9 A through C). Once broken down into individual pigments better insight into composition was revealed. Fucoxanthin was shown to be the principal pigment throughout most of the year reporting only two shifts in composition dominance. Winter months demonstrated the lowest levels of fucoxanthin, while summer reported distinct peaks in concentration. The dominance of fucoxanthin demonstrated a community dominated by diatoms throughout most of the year. This domination is most apparent during the spring and summer when elevation in percent composition as well as total concentration was reported. These increases during the spring and summer suggest the onset of upwelling and demonstrate its effect on both composition and concentration.

Diadinoxanthin was the second most abundant pigment reported (Fig. 9 A). Levels strongly mirrored those of fucoxanthin throughout the study. Levels of diadinoxanthin, a solar protective pigment also revealed elevated values as summer approached corresponding to increasing insolation during this time. Peridinin was the third most abundant pigment reported. Levels of peridinin were opposite to those of fucoxanthin, reporting highest values during the winter and lowest during the summer. 
Elevated levels of peridinin during the winter revealed an increased dinoflagellate composition, leading up to the first of two composition shifts reported during the study. Both shifts demonstrate dramatic declines in fucoxanthin coupled with increases in peridinin. This occurrence of offset peaks suggests that diatoms and dinoflagellates flourish under different conditions. Concentrations of diatoxanthin, alloxanthin, hexanoyloxyfucoxanthin, prasinoxanthin, zeaxanthin, butanoyloxyfucoxanthin, neoxanthin, violaxanthin, and lutenin were additionally reported however; relative concentrations were low and insignificant to the study (Fig. 9A through 9C).

The use of microscopy provided another method of composition analysis. Unlike HPLC, microscopy allows for identification to the species level. However, difficulties arise when attempting to identify cells smaller than $10 \mathrm{um}$. Community structure as reported by microscopy analysis demonstrated seasonal shifts in composition. Phytoplankton concentration during the winter showed relatively low numbers primarily dominated by dinoflagellates. Between 60 and 90 percent of the community structure during this time consisted of a variety of dinoflagellates. By mid-spring decreasing dinoflagellate concentrations and increasing diatom concentrations became apparent demonstrating a more balanced community. Samples obtained during the late spring and summer demonstrated a dramatic shift in composition with a diatom composition of over 85 percent (Fig. 9D).

Community structure in San Luis Obispo Bay appears to be closely related to the hydrographic seasons. Both sampling methods revealed lower biomass but increased diversity including increases in dinoflagellate composition during the winter. Winter months had high levels of diatoms such as Psuedonitzchia and Eucampia as well as the 
dinoflagellates Peridinium and Prorocentrum. The approach of spring and the onset of upwelling revealed a community that was largely diatom dominated. This period reported similar diatom species present during the winter but also included Chaeocerotos, Leptocylindrus, and Skeletenoma. These findings are consistent with similar coastal upwelling regions and suggest that species reported during upwelling are typical of the first stage of succession (Schrader 1981).

Other coastal projects provide further evidence for the dominance of diatoms in these upwelling systems. In each case, direct observation supports the idea that diatoms are the workhorses for these biological communities accounting for the majority of the biomass (Kudela et al., 1997).

Additionally it appears that increased diversity was associated with decreased

diatom dominance (Fig. 9). This demonstrates the competitive advantage of diatoms and their ability to exploit the favorable upwelling conditions. Increased diversity also appeared to follow periods of relaxation suggesting the association between advection and displacement by species typical to the later stages of succession (Schrader 1981).

\section{Study period REMUS}

In addition to examining the seasonal scale changes in surface water physical and biological dynamics, it was important to also sample sub surface at a high enough temporal resolution to resolve a single cycle of accumulation and loss within San Luis Obispo Bay. To do this, we examined all of the previously reported physical and biological data using an additional sampling platform, the REMUS AUV. The use of the REMUS AUV allowed us to explore the process by measuring a variety of variables over time, distance, and depth (Fig 10A through 10C). The inclusion of depth as later 
described will be shown to be a vital component when accurately quantifying phytoplankton concentration in San Luis Obispo Bay.

$05 / 18 / 2004$

The inaugural mission of this study was designed to get the REMUS 100 in the water and work out any difficulties that may become prevalent in later and subsequently more important missions. The mission began on 05/18/2004 at 11:28:02 am. The REMUS 100 traveled a distance of 3862 meters $(2.09 \mathrm{~nm})$, which was covered in 28 minutes 39 seconds yielding an average velocity of 2.2 meters/sec. (4.4 knots). The REMUS 100 dove to a depth of $4 \mathrm{~m}$ from the surface for the entire duration of the mission. The mission appeared to go smoothly as the REMUS 100 departed and returned without a noticeable incident however; later analysis revealed that some changes needed to be made.

Upon analysis of acoustic fixation, it was determined that transponder $\mathrm{H}$ was not being properly recognized. As the REMUS 100 neared waypoint 3 it began to reach the maximum distance from which it could triangulate its position using transponder $\mathrm{G}$ and D. At this point the REMUS 100 should have recognized transponder $\mathrm{H}$ but failed to and thus began to rely on its dead reckoning capability. Once the REMUS 100 completed it's programmed turn at waypoint 4 , it began to recognize transponders $\mathrm{G}$ and $\mathrm{D}$ again and was able to triangulate its position using acoustic fixation. Transponder $\mathrm{H}$ was later removed and shipped for repair.

In addition to working out any glitches, the route was directed alongshore to the east in hopes of crossing the edge of our proposed plankton plume. Measurements of chlorophyll $a$ demonstrated blotchy localization but failed to yield a distinct plume edge. 
$06 / 04 / 2004$

After the faults from the inaugural run had been fixed, the series of designed missions began. The first began on 06/04/2004 at 11:18 am. The REMUS 100 traveled a distance of 13622 meters $(7.36 \mathrm{~nm})$, which was covered in 1:40.08 yielding an average velocity of 3 meters/sec. (4.4 knots). The REMUS 100 completed leg 1 of the mission at the surface and then dove to a depth of 1 meter from the surface for legs 2,3 , and 4 . It then completed legs 5 and 6 and by oscillating from the surface to within $4 \mathrm{~m}$ of the bottom. The REMUS 100 would then complete its mission by rising to 1 meter of the surface to finish leg 7.

The offshore run demonstrated fairly constant chlorophyll concentrations with values ranging from approximately $(0.05 \mu \mathrm{g} / \mathrm{L})$ to $(2.0 \mu \mathrm{g} / \mathrm{L})$. Slight fluctuations were apparent but the overall trend appeared to be that concentrations slightly increased as the distance offshore increased. The onshore return of the REMUS 100 demonstrated varying chlorophyll a concentrations as the REMUS 100 began its undulations. As the REMUS 100 began its initial descent the measured chlorophyll concentration rose until reaching a peak, and then began to fall. Likewise as the REMUS 100 began its ascent, chlorophyll concentrations increased until reaching a peak and then fell again as the REMUS 100 neared the surface. As the REMUS 100 repeated its undulations this process was demonstrated repeatedly resulting in a series of bimodal curves. These findings reveal the presence of a subsurface chlorophyll layer where the maximum chlorophyll concentration was located at a depth below that of the surface. As the REMUS 100 returned a peak chlorophyll concentration of $(10.36 \mu \mathrm{g} / \mathrm{L})$ was encountered at approximately $1 \mathrm{hr}$ and 30 minutes into the mission 
$06 / 07 / 2004$

Mission number two took place on 06/07/2004 at 9:51.58. The REMUS 100 traveled a distance of 13744 meters $(7.42 \mathrm{~nm})$ in 1:41.56 at a speed of 2.2 meters/sec. (4.4 knots). The REMUS 100 completed leg1 of the mission at the surface. After encountering a vessel in the vicinity on the previous deployment, the depth of leg 2 and 7 were changed to 3 meters to prevent the likelihood of collision. The offshore depth of legs 3 and 4 were kept at 1 meter from the surface, while the onshore return of legs 5 and 6 remained oscillatory from the surface to within $4 \mathrm{~m}$ of the bottom.

The offshore run demonstrated an increase in chlorophyll concentration at around 25 minutes into the mission. The spike ranged from just below $(.5 \mu \mathrm{g} / \mathrm{L})$ to approximately $(1.75 \mu \mathrm{g} / \mathrm{L})$.The onshore return recorded this near-surface peak, but also showed increasing subsurface concentrations as the REMUS 100 returned. As in the previous run, findings demonstrate the presence of subsurface chlorophyll with higher chlorophyll concentrations than those at the surface. Chlorophyll concentrations encountered during this mission were relatively low, with maximum concentrations reaching $(4.22 \mu \mathrm{g} / \mathrm{L})$.

$06 / 10 / 2004$

The 06/10/2004 mission began at 9:38.51 a.m. and covered a distance of 13574 meters $(7.33 \mathrm{~nm})$ in 1:39.13. The average speed of the REMUS 100 was 2.3 meters/second (4.4 knots). The REMUS 100 completed leg 1 at the surface and then dove to a depth of 3 meters from the surface for leg 2, elevated slightly to a depth of 1 meter from the surface for legs 3 and 4 , and oscillated from the surface to within 4 meters of the bottom for legs 5 to 7. 
The offshore run demonstrated slight changes in chlorophyll concentration ranging from values just above zero to values of $(1.75 \mu \mathrm{g} / \mathrm{L})$. The onshore return showed immediate chlorophyll spikes as the REMUS 100 began to oscillate. Values of (5.03 $\mu \mathrm{g} / \mathrm{L})$ were reached upon the first oscillation and gradually began to decrease as the REMUS 100 neared the shoreline suggesting that the chlorophyll layer was located at a subsurface depth and toward the offshore end of the mission. As in all previous missions the chlorophyll spikes were bimodal representing a subsurface chlorophyll layer.

$06 / 14 / 2004$

The 06/14/2004 mission began at 9:14.06 am and covered a distance of 13644 meters $(7.37 \mathrm{~nm})$ in 2:04.04. The average speed of the REMUS 100 was 1.8 meters/second (1.6 knots). The REMUS 100 completed leg 1 at the surface, dove to a depth of 3 meters from the surface for leg 2, elevated slightly to a depth of 1 meter from the surface for legs 3 and 4, and oscillated from the surface to within 4 meters of the bottom for legs 5 and 7.

The offshore run demonstrated a fairly constant chlorophyll level of approximately $(1.75 \mu \mathrm{g} / \mathrm{L})$. As the REMUS 100 began its oscillatory return chlorophyll concentration began to rise slightly reaching a value of just above $(2.24 \mu \mathrm{g} / \mathrm{L})$ on its first oscillation. As the REMUS 100 neared the shore the chlorophyll values began to increase, reaching a maximum value of $(7.13 \mu \mathrm{g} / \mathrm{L})$ on the last upward oscillation. Once again the data suggested that the highest chlorophyll concentrations were subsurface. 
$06 / 16 / 2004$

The 06/16/2004 mission began at 7:32.18 and covered a distance of 13727 meters $(7.41 \mathrm{~nm})$ in 1:41.09. The average speed of the REMUS 100 was 2.3 meters/ second (4.4 knots). The REMUS 100 completed leg 1 at the surface, dove to a depth of 3 meters from the surface for leg 2, elevated slightly to a depth of 1 meter from the surface for legs 3 and 4 , and oscillated from the surface to within 4 meters of the bottom for legs 5 to 7 .

The offshore run demonstrated chlorophyll a values starting at approximately (2 $\mu \mathrm{g} / \mathrm{L})$ and rising to $(5.92 \mu \mathrm{g} / \mathrm{L})$ as the REMUS 100 reached the offshore endpoint. As the REMUS 100 began its onshore return and oscillations, chlorophyll a values rose to $(9.51 \mu \mathrm{g} / \mathrm{L})$ and then fell off to $(5.90 \mu \mathrm{g} / \mathrm{L})$ before rising back to $(11.42 \mu \mathrm{g} / \mathrm{L})$ as it neared the shore. Values then dropped off to $(4.33 \mu \mathrm{g} / \mathrm{L})$ as the nearshore endpoint was reached. These results demonstrate the presence of two peaks in chlorophyll concentration. One peak was near the offshore endpoint and the other near the half point, both at a subsurface level as demonstrated by bimodal peaks.

\section{REMUS Findings}

Deployment of the REMUS revealed findings that would have been difficult to observe with other methods of phytoplankton sampling. The presence of an initial subsurface chlorophyll layer was reported during our first mission as elevated nearshore chlorophyll concentrations (fig. 10C). This presence of this layer suggests that complete advection from a previous cycle had not occurred. Subsequent missions demonstrated movement of this layer offshore and its dispersal suggesting possible advection. Our final mission reported the presence of a secondary sub-surface chlorophyll layer, suggesting accumulation and the onset of a new cycle. 
In order to determine if phytoplankton dispersal was due to the advection of this primary layer, we examined the relationship between salinity (a conservative tracer) and temperature. Findings demonstrated unique density signatures reported from each of our five missions (Fig. 15A \& B). LeBlond et al. (1990) showed that intrusions in the Straight of Georgia were clearly identifiable due to variation in temperature and salinity. In San Luis Obispo Bay this seems to be the case as colder denser waters were reported on $6 / 10 / 2004$. These cold dense waters coincided with an episode of wind relaxation suggesting displacement of water due to a small upwelling event. Density signatures following this upwelling event demonstrated warmer fresher water suggesting intrusion by poleward movement. These two separate mechanisms suggest that water replacement in the bay is a dynamic multifaceted process.

In addition to transport, other factors may contribute to phytoplankton declines. Grazing is perhaps the most well described process of phytoplankton declines, next to advection (Jassby and Golden 1974). Slaughter et al. (2006) estimated zooplankton grazing rates with the gut fluorescence method; they found that this community could account for greater than $100 \%$ of phytoplankton standing stock per day during prolonged wind relaxation, but more typically consumed $25-38 \%$ of standing stock per day during stronger upwelling events when a greater loss of phytoplankton from shelf. Jassby and Golden (1974) suggest that accurate modeling of the phytoplankton loss rate can be attributed to transport, sinking and grazing alone, and are the only processes other than growth that need to be incorporated into mathematical models.

Other possible processes, such as cellular breakdown and decomposition when environmental tolerances are exceeded and cell death through parasitism, are almost 
always absent from mathematical models (Jassby and Golden 1974). For example, Patten (1968) included only two cases in which cell mortality due to mechanisms other than zooplankton grazing were mentioned. In one of these, mortality was assumed to be negligible in the application of the model (Cushing 1959) and in the other, only hypothetical parameters were used (Patten 1968) (Jassby and Golden 1974).

\section{Study Period Physical Data}

Once REMUS missions were completed, further analysis of the concurrent physical and biological data was performed. Data presented during this time frame was termed "study period," and consisted of data collected from 6/1/2004 through 6/22/2004. The goal of examining data over this time scale was to identify the process over a single cycle.

Physical data reported during our study period supports cyclical phytoplankton accumulation and advection patterns and demonstrates the process over a single cycle. Wind data during this period demonstrated a constant equatorial force giving way to one complete shift in direction. This shift in direction began on 6/15/2004 and lasted approximately 4 days before it returned equatorial (Fig. 12C). Wind speed during this time reported two periods of relaxation, one on 6/10/2004 and one on 6/15/2004. The second relaxation period coincided with a directional shift in wind while the first did not (Fig. 12C \& 12D).

SST showed a distinct coupling with wind forcing. On 6/10/2004 SST values reported declines concurrent with the first period of wind relaxation. Values after this period rose until 6/15/2004 when they again reported declines concurrent with the second period of wind relaxation (Fig. 12A). Relative SST values report nearshore elevations 
during equatorial forcing while a reversal of this pattern was shown during relaxation, as offshore increases were reported (Fig. 12B).

As described in our seasonal physical data findings, the relationship between wind stress and SST is well defined. The process of relaxation typically consists of two components, a shift in direction and a decrease in velocity. Analysis during our study period suggests that although direction may be an indicator of the process, velocity appears to be the driving force. In addition the strong correlation between relative SST values and velocity suggests the occurrence of a warm water intrusion and the associated temporal lag of this water.

\section{Study Period Biomass}

Satellite data, HPLC pigment data, microscopy, and REMUS data were all implemented during our study period in an attempt to accurately estimate biomass and quantify the process in San Luis Obispo Bay. All methods demonstrate initial declines followed by increases in biomass (Fig. 13A through 13D). REMUS chlorophyll a was the only method that failed to demonstrate a peak in biomass followed by a secondary decrease. However, the onset of this decline as measured by the other methods commenced after 6/16/2004 while REMUS chlorophyll a data was only collected up until this date (Fig. 11A). Measurements taken after REMUS missions via Satellite, HPLC, and Microscopy demonstrate declining concentrations of chlorophyll a and cell number (Fig. 13A through 13D).

On the biological level, biomass demonstrated a direct coupling to the physical model. Phytoplankton accumulation was reported during equatorial wind forcing through relaxation. Findings are consistent with our hypothesis of accumulation during periods of 
insolation and retention. Post relaxation led to phytoplankton concentration decreases suggesting dispersal and advection associated with upwelling. All methods appeared to correlate well with reported physical data, as well as with each other suggesting that each individually, is a valid means of concentration measurement.

\section{Study Period Community Structure}

Two methods of composition analysis were used during our study period in order to accurately determine community structure. Microscopy revealed a community strongly dominated by diatoms throughout the majority of our study period. As our study period proceeded, elevations in dinoflagellate composition were reported in junction decreases in diatom concentration (Fig. 14D). Taxonomic identification revealed the presence of Chaetoceros as well as chain forming diatoms including, Psuedonitzchia, Leptocylindeus, Stephanopysis and Eucampia. This composition is similar to other reports along the California coast during this time of year, Alldredge and Gotschalk (1989), who found that aggregations of setose genus Chaetoceros and chain-forming Nitzschia are common to the California coast during this time and due to their fast growth and ability to out compete other species.

Phytoplankton pigmentation mirrored microscopy reporting initially elevated levels of fucoxanthin demonstrating a community dominated by diatoms. However; as our study period proceeded, fucoxanthin levels dropped revealing a more balanced and more diverse community . During this drop in fucoxanthanin, levels of peridinin and alloxanthanin rose revealing an increase in dinoflagellate and cryptophyte composition. This event led to a significant shift in composition dominance (Fig. 14A through 14C). 
Community structure reported coupling to the physical model. Both sampling methods report low initial diversity during insolation and retention, suggesting a community dominated by the early stages of succession. The period associated with upwelling demonstrated dramatic decreases in chlorophyll concentration however; little change in diversity was reported. Diversity levels increased post relaxation revealing an influx of phytoplankton typical to the later stages of succession. This shift in composition varies from that commonly associated with upwelling and suggests water replacement due to poleward transport. In order to further examine the mechanism(s) of this process we compared community structure to salinity and temperature at both surface and bottom layers of the inner harbor.

\section{Describing the Mechanism(s)}

In order to accurately illustrate the mechanism(s) of water replacement, we constructed salinity-temperature plots isolating the surface $3 \mathrm{~m}$ and bottom $3 \mathrm{~m}$ data of our REMUS missions (Fig. 15A \& 15B). By isolating the water column data into these two classifications, we were able to observe the evolution of both the surface and bottom water in order to identify the mechanism(s) of water replacement. These plots reveal the occurrence of upwelling on 6/10/2004. This cool saline water arrives in junction with relaxation in the local wind field. Biomass during this time reports a dramatic decrease while diversity reports no significant change. Findings suggest an intrusion of phytoplankton poor waters associated with upwelling. Samples following this upwelling event show a warmer less saline signature and suggest poleward water replacement. Phytoplankton diversity during this time also demonstrated a dramatic shift in composition revealing an influx typical to the later stages of succession. This coupling of 
increased diversity and unique density signatures demonstrates that although upwelling may be responsible for an initial flushing of the system, poleward movement follows seeding the bay and influencing composition. The rapid shifts in both temperature and salinity demonstrate two distinct water replacement events. The degree and speed of these events can only be explained by water replacement enabling us to identify two distinct mechanisms. The presence and identification of two separate mechanisms for water replacement demonstrates the complex and dynamic conditions found in San Luis Obispo Bay (Fig. 16).

\section{Summary and Conclusion}

San Luis Obispo Bay appears to experience many of the seasonal physical and biological conditions common to the California Coast. During the winter when strong winds and erratic southerly storms are prevalent, water temperatures are relatively stable and low. Phytoplankton concentrations during this time are also low, and there is a mixed composition of diatoms and dinoflagellates.

Spring and summer brings persistently equatorial winds and a reduction of wind relaxation. Water temperatures during this time become elevated suggesting limited mixing and the effects of insolation. Phytoplankton concentrations during this time are cyclic and elevated consisting of a community dominated by diatoms.

The common coastal occurrence of upwelling and the cool temperatures associated with it appears to be influenced by the bay's local topography including the presence of a lee. This influence creates retentive conditions similar to other described “phytoplankton bloom incubation areas" (Ryan et al. 2008). 
On a single cycle scale, we have shown the model of phytoplankton dynamics in San Luis Obispo Bay to be valid. Through, multi-scale, multidisciplinary observations, we have presented a clear physical and biological coupling in the time series data. The result is a model that yields phytoplankton accumulation during periods of insolation and retention followed by dispersal during upwelling and subsequent advection. Poleward water replacement was demonstrated following upwelling and suggests that although upwelling appears to initially flush the system, this northward water replacement drives biology of this system.

This study revealed new insight to phytoplankton dynamics in San Luis Obispo Bay. However, further research is required to more completely understand this complex and varying process. San Luis Obispo Bay lies in the heart of a highly productive coastal upwelling system that has received considerable oceanographic study because of its fisheries and proximity to large human populations (Chavez et al. 2000). Although this study included observations on a local scale only, it has been shown that small-scale local occurrences may influence larger scale processes (Ryan et al. 2005). This suggests that the validity of these results may have larger coastal-scale implications. 


\section{FIGURES}

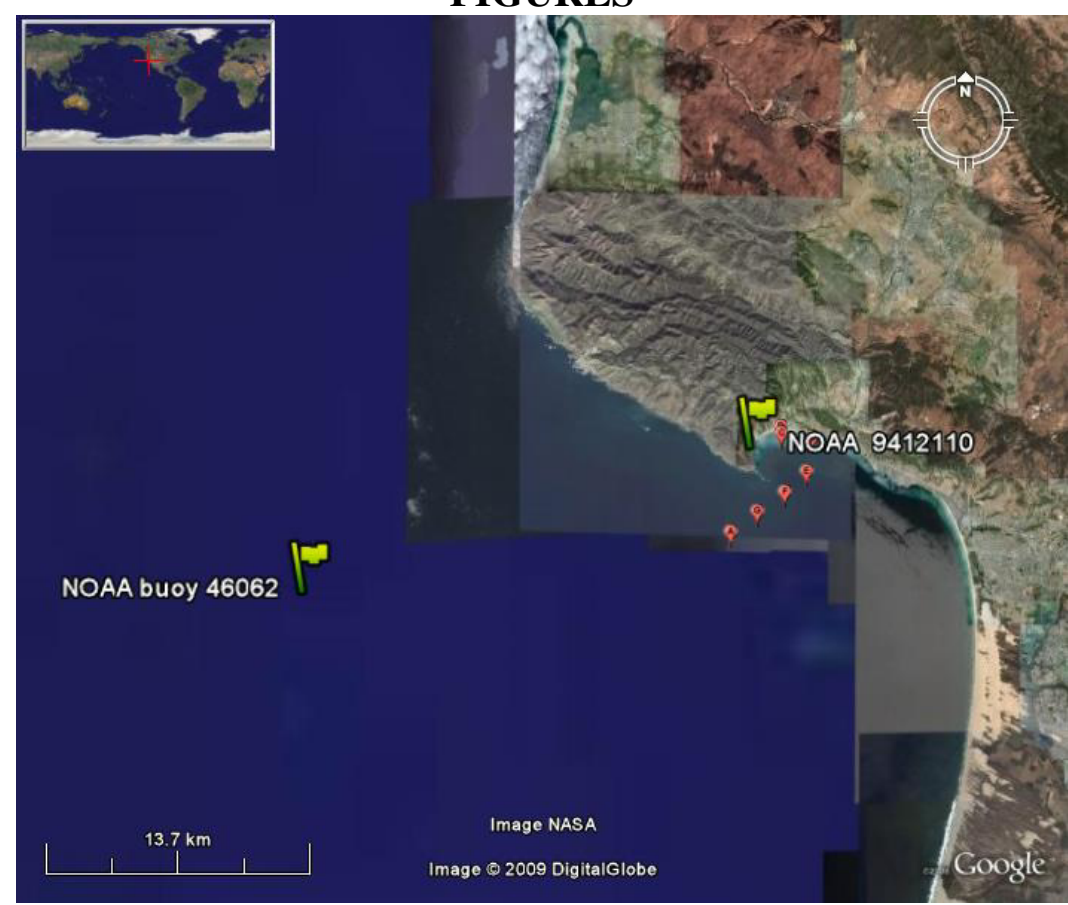

A)

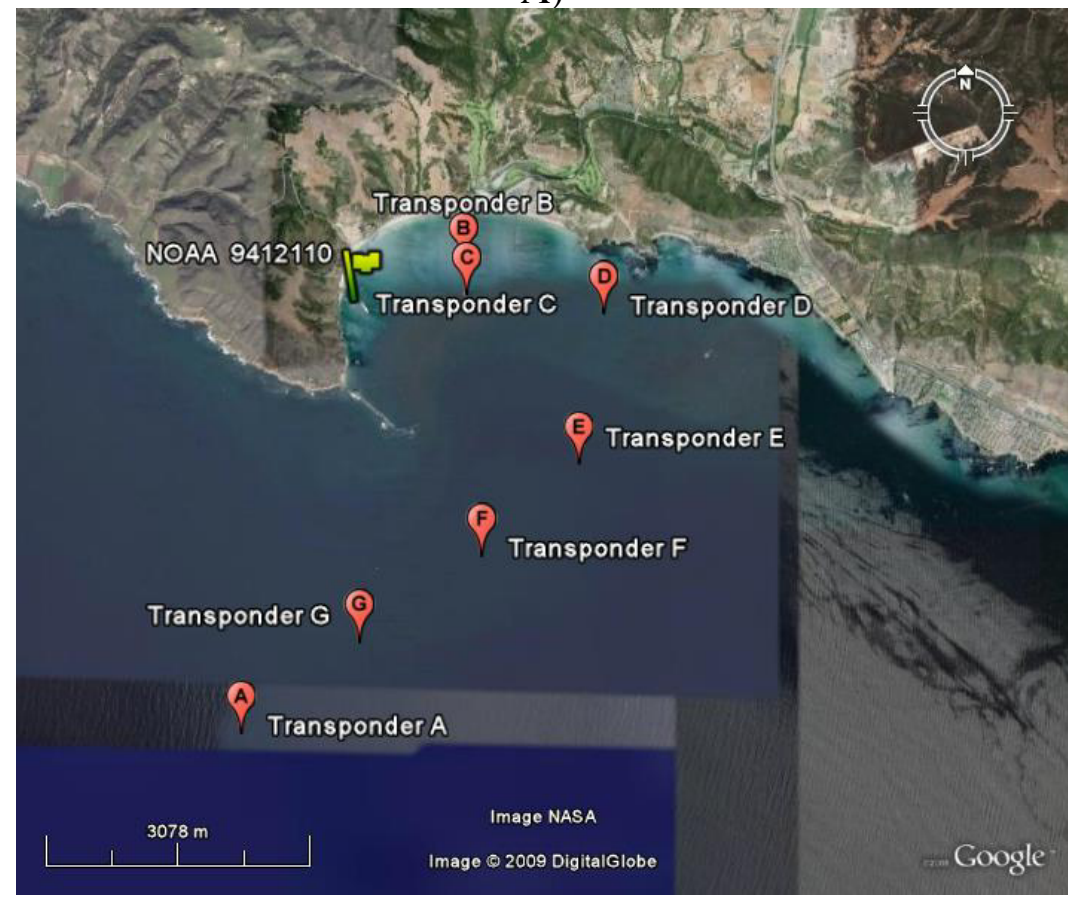

B)

Figure 1. A) Location of NOAA buoy $46062(4606235.101 N, 121.010 W)$ and NOAA temperature gauge 9412110 (35.169N, 120.754W) relative to the San Luis Obispo Bay and the California coast. B)

Transponder location. Transponders $\mathrm{B}$ and $\mathrm{C}$ were deployed from the research facility pier and located at 35.1728N 120.7411W and 35.1697N 120.7407W. Transponders D, E, F, G, and A were fixed via mooring and deployed at $35.1677 \mathrm{~N} 120.7231 \mathrm{~W}, 35.1519 \mathrm{~N} 120.7263 \mathrm{~W}, 35.1423 \mathrm{~N} 120.7388 \mathrm{~W}$, 35.1333N 120.7545W, and 35.1237N 120.7697W. 


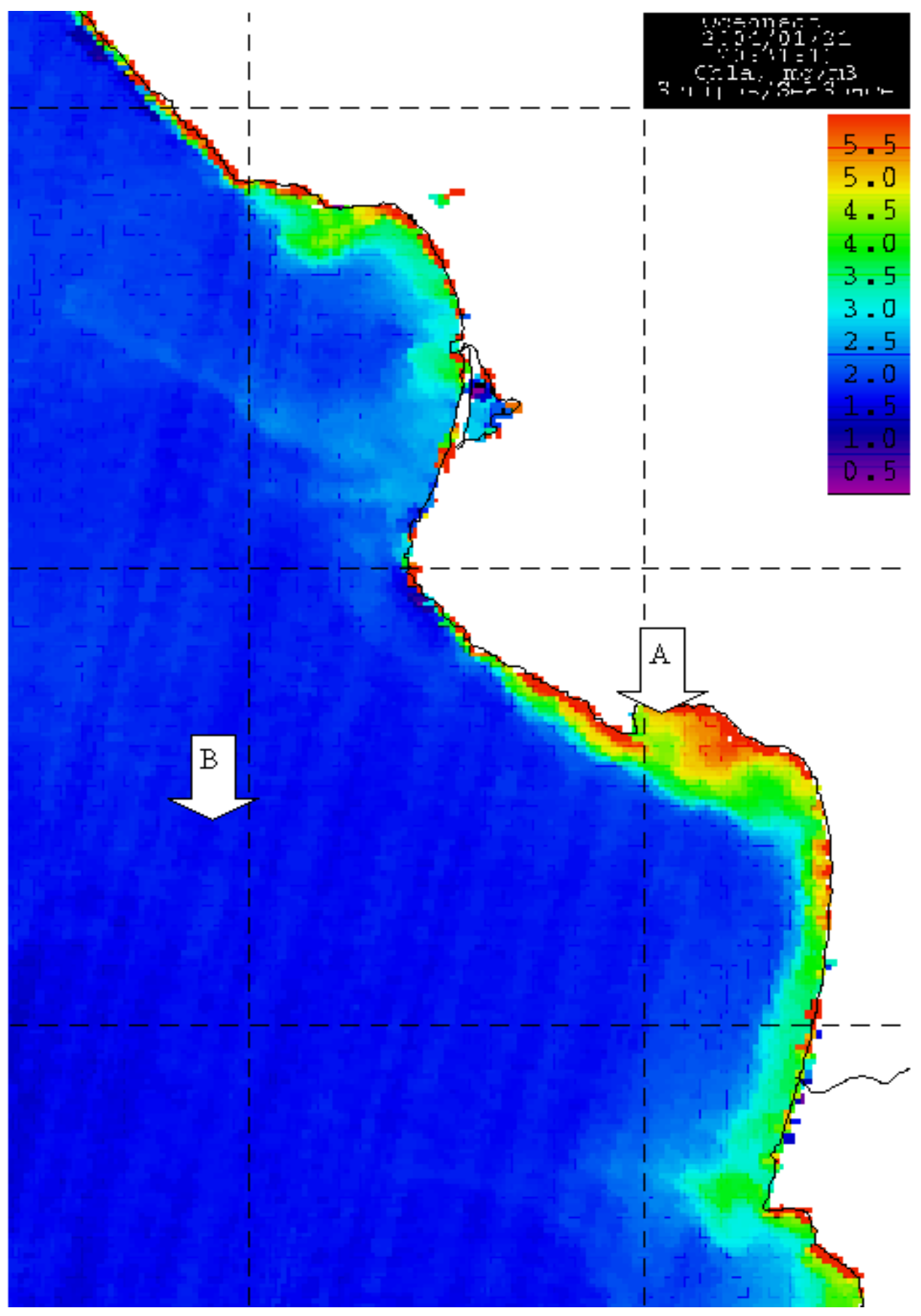

Figure 2. Oceansat-1 OCM image taken on 1/21/2004 showing nearshore and offshore sampling points for satellite imagery analysis.. Point $A$ (nearshore) was located at the end of the Cal Poly Center for Coastal Marine Sciences pier facility $(35.1697 \mathrm{~N} 120.7407 \mathrm{~W})$, while point B (offshore) was located at NOAA buoy $46062(35.101 \mathrm{~N}, 121.010 \mathrm{~W})$. 


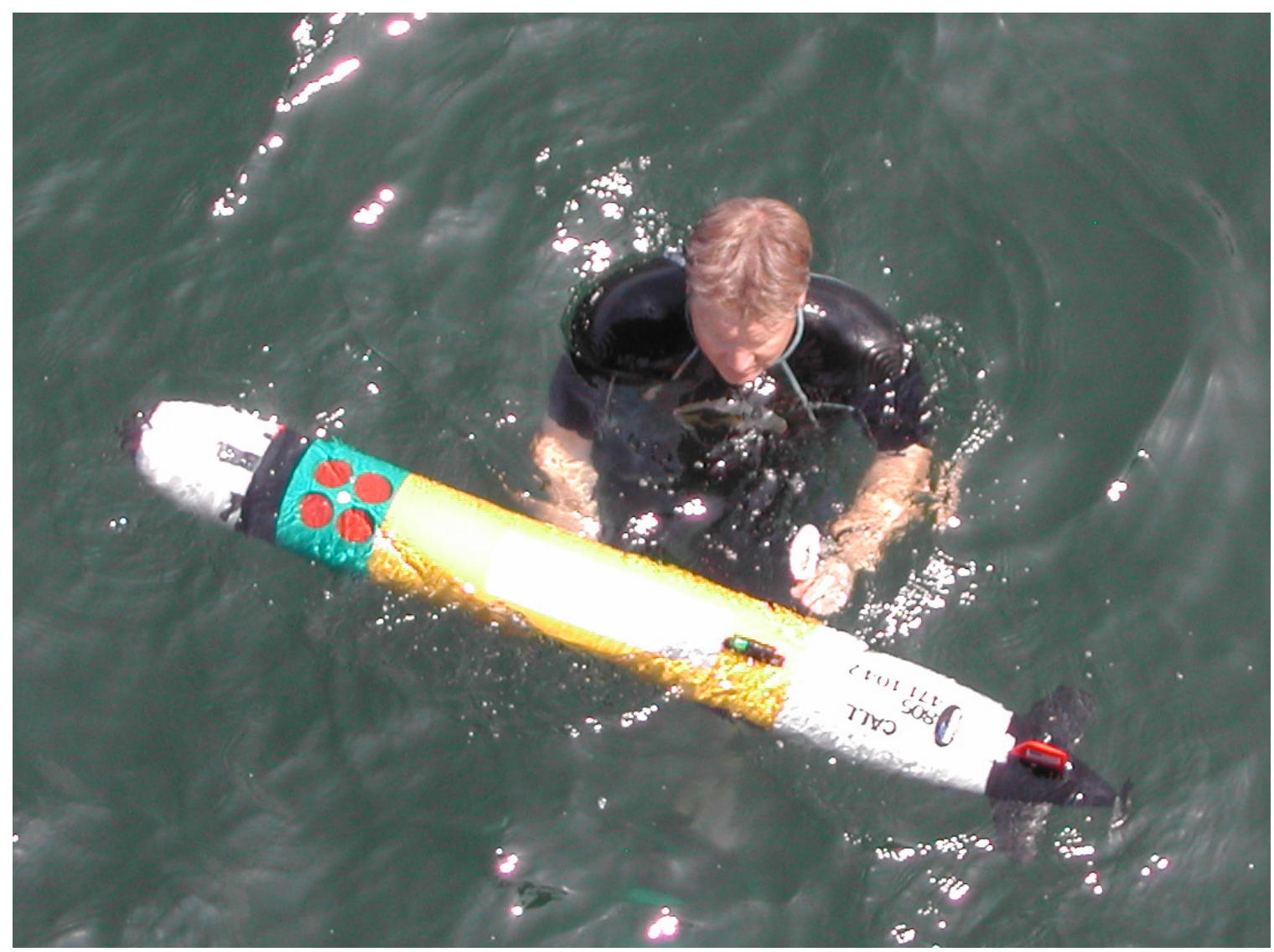

Figure 3. Deployment of REMUS 100 AUV during June 2004. Instrumentation includes a CTD and a fluorometer/backscatter sensor. Total vehicle length was $3.0 \mathrm{~m}$. 
A)

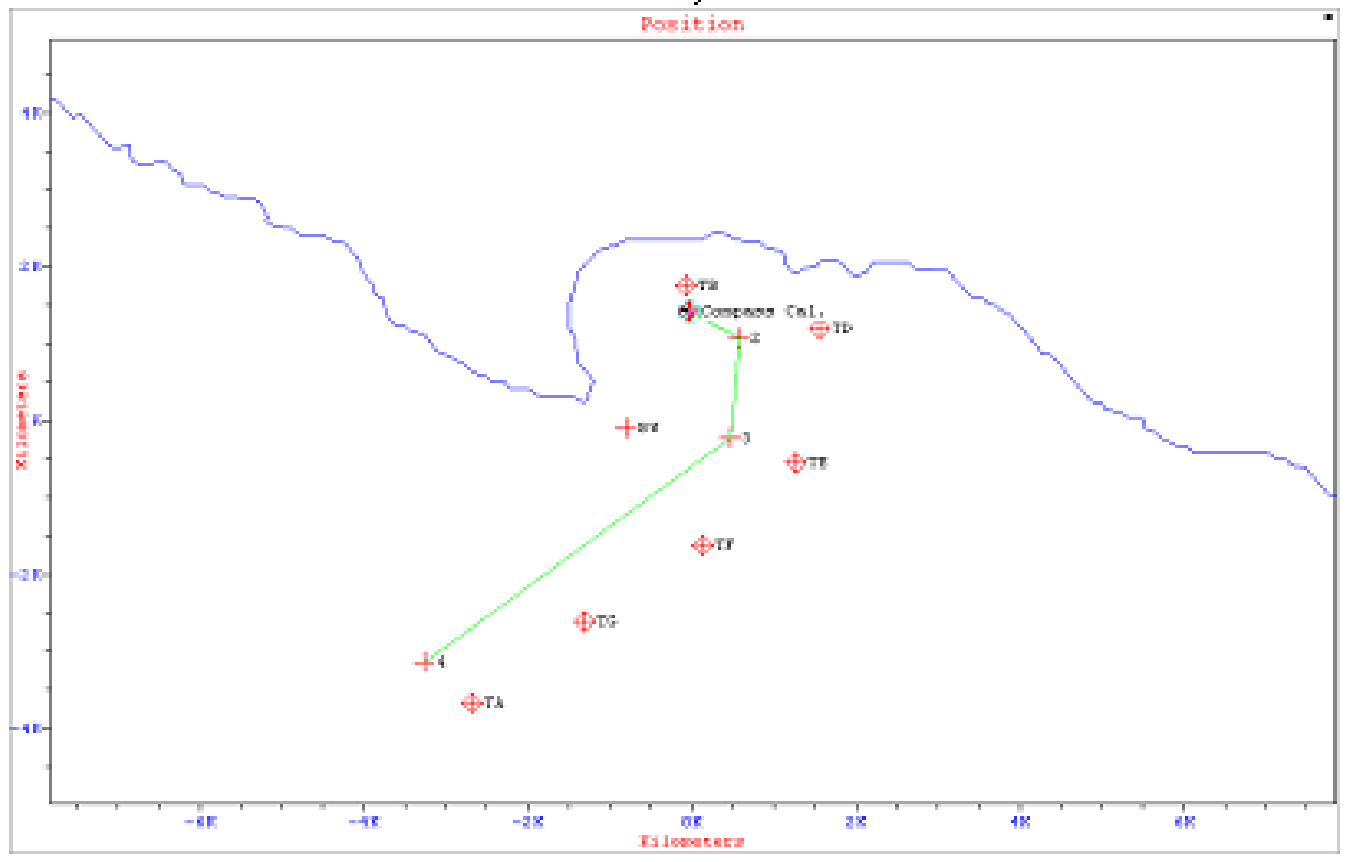

B)

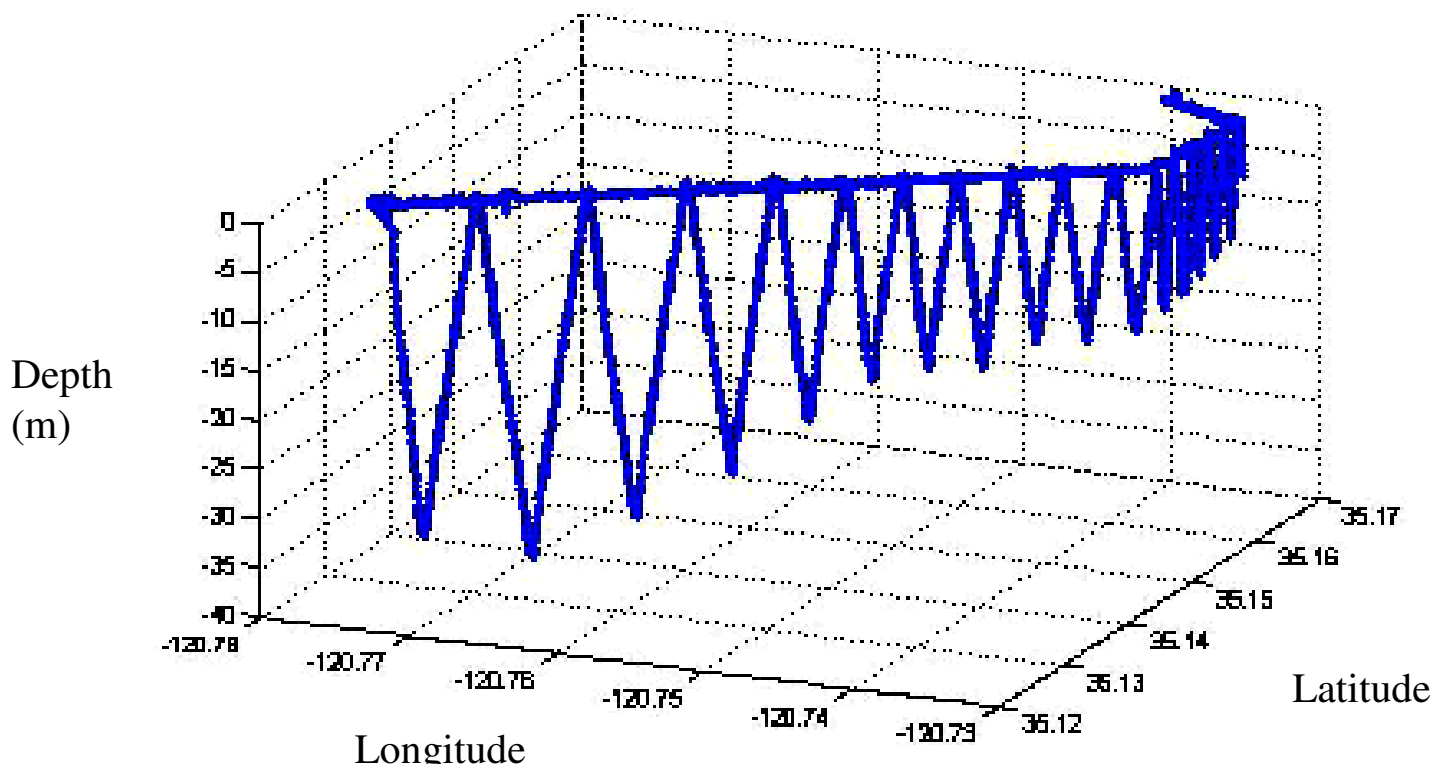

Figure 4. A) Map of the REMUS mission track used in this study. The transponder locations are shown in red. Missions were J-shaped in order for the vehicle to safely clear the tip of the break-wall (BW on figure) located in the northwest corner of the bay. B) REMUS mission depth map showing its surface position (flat line) as it moved offshore followed by its undulating return (jagged line). 
Float

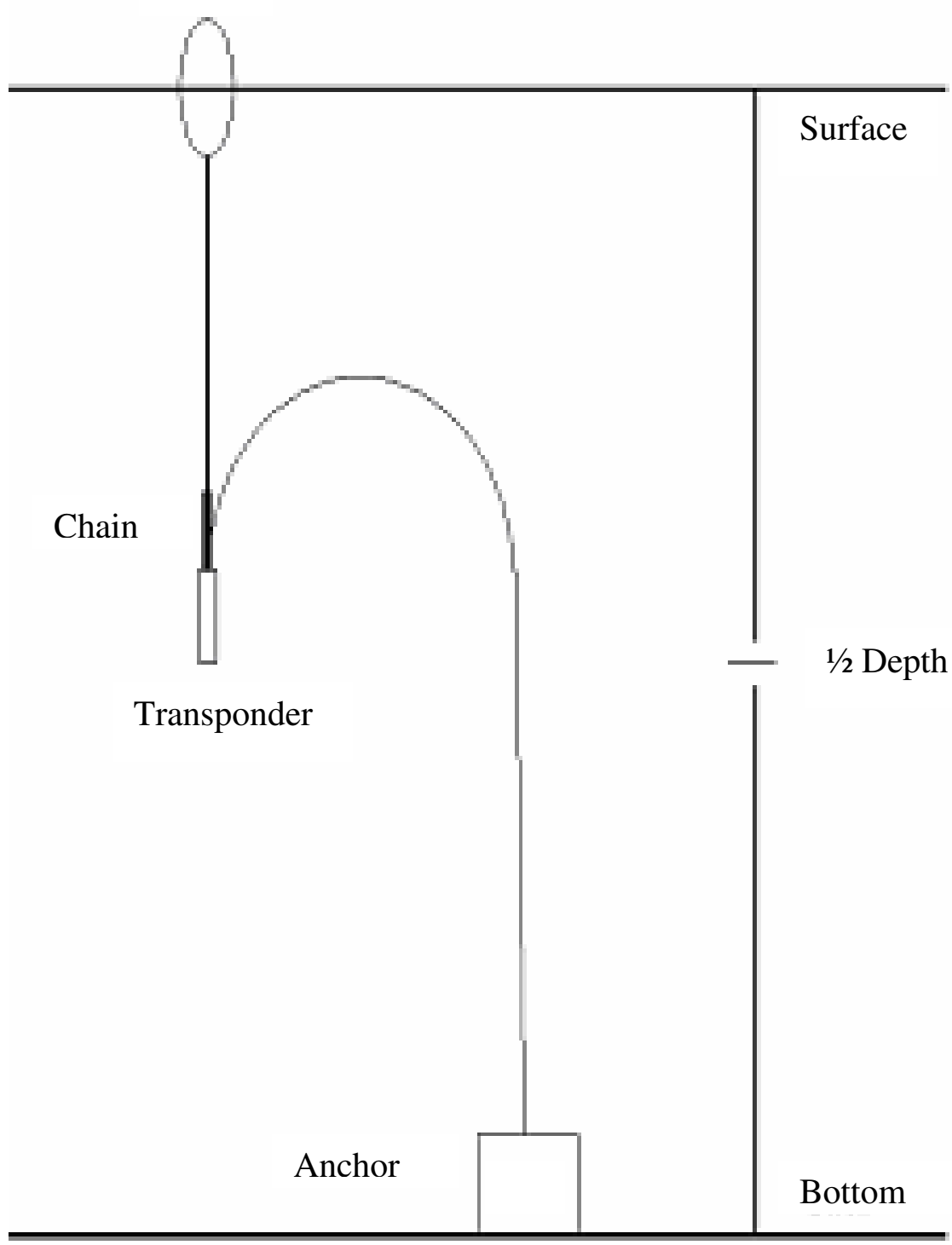

Figure 5. Mooring design allowing for easy replacement of transponders without disturbance of mooring. Deployed transponders were positioned at approximately one half the depth of the water column, which was the mid-point of the REMUS operations to optimize communication and navigation. 
A) Sea Surface Temperature
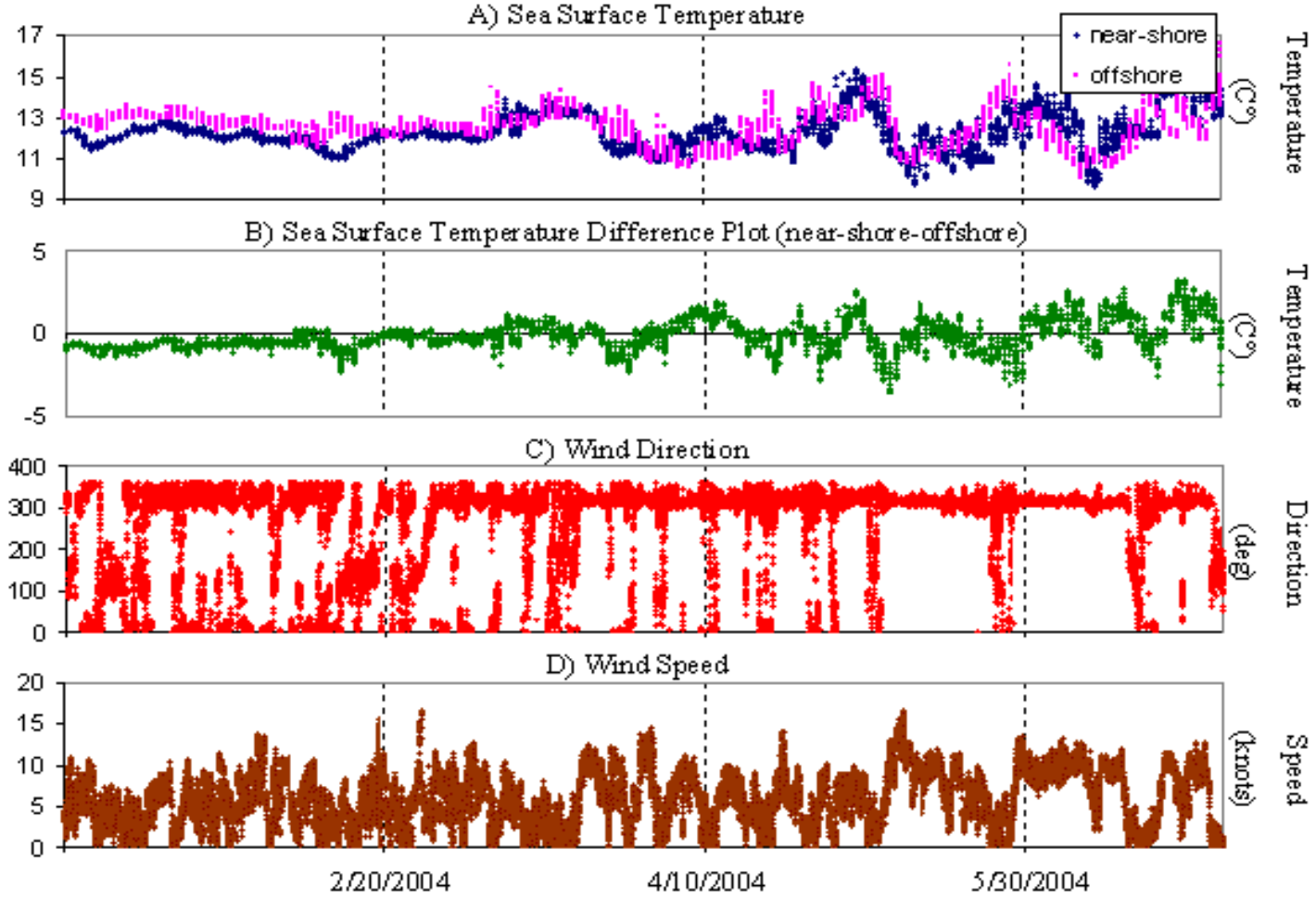

Figure 6. Physical data reported from 1/1/2004 to 6/30/2004. A) Sea surface temperature plot from 1/1/2004 through 6/30/2004 demonstrating low stable values during the winter and elevated

fluctuating values during the summer. (Nearshore) measurements (blue) were reported from NOAA temperature gauge 9412110 while offshore measurements (pink) were reported from NOAA buoy 46062 (offshore). B) Difference plot demonstrating increases in SST fluctuation as summer approached. Temperature is reported as (nearshore-offshore). C) Wind data showing directional dominance from between 300 and 350 degrees. Data also demonstrates elongated periods between shifts reported during the late spring and summer. D) Wind speed data showing relaxation periods corresponding to shifts in wind direction. 


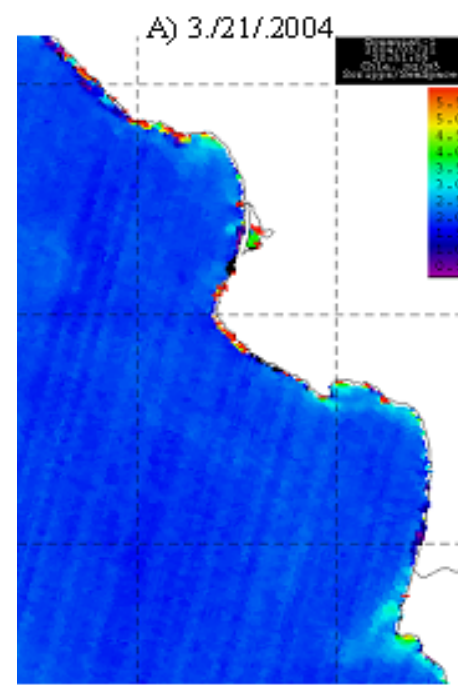

B) $3.25 / 2004$

\section{C) $3.27 / 2004$}
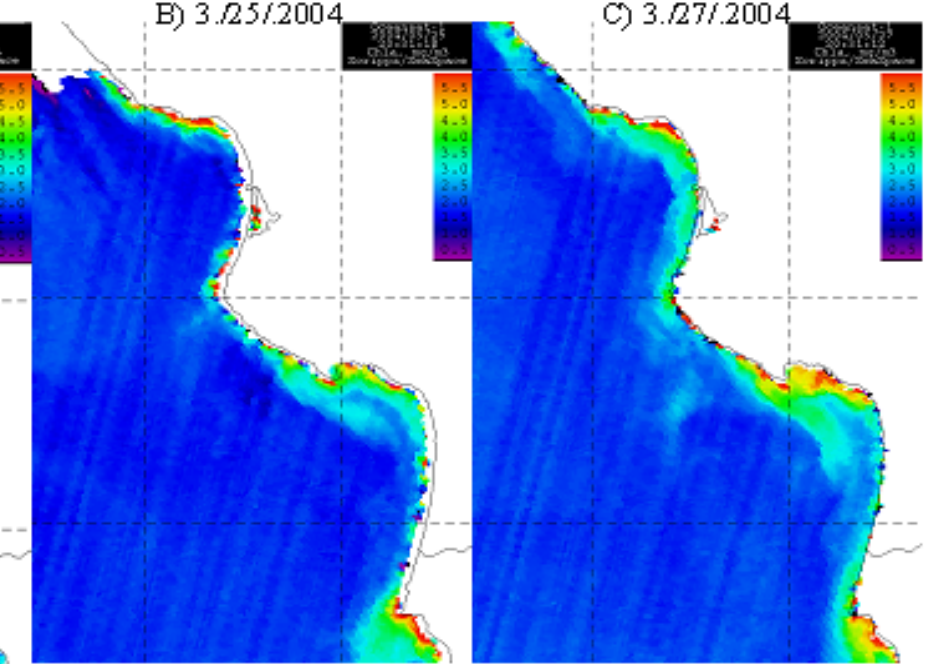

D) $3 . / 31 / 2004$

E) $4 . / 2 / 2004$

F) $4 / 6 / 2004$

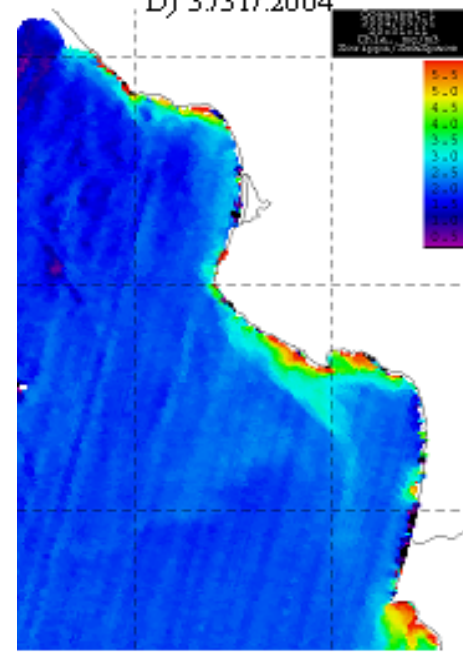

E) 4.21 .2004 \%

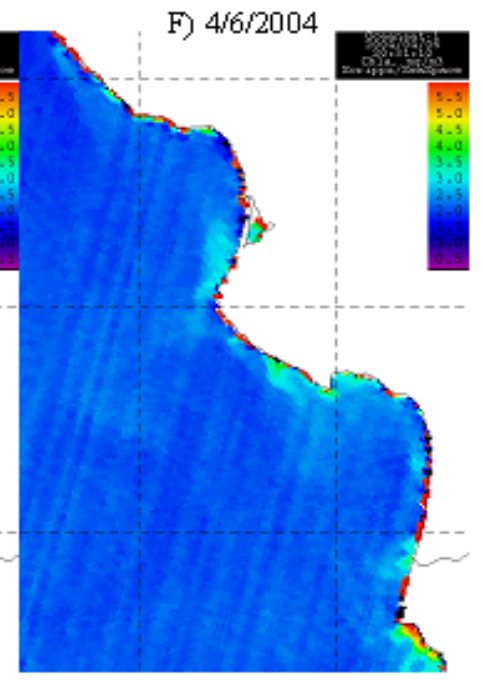

G) Satellite Chloronhril a

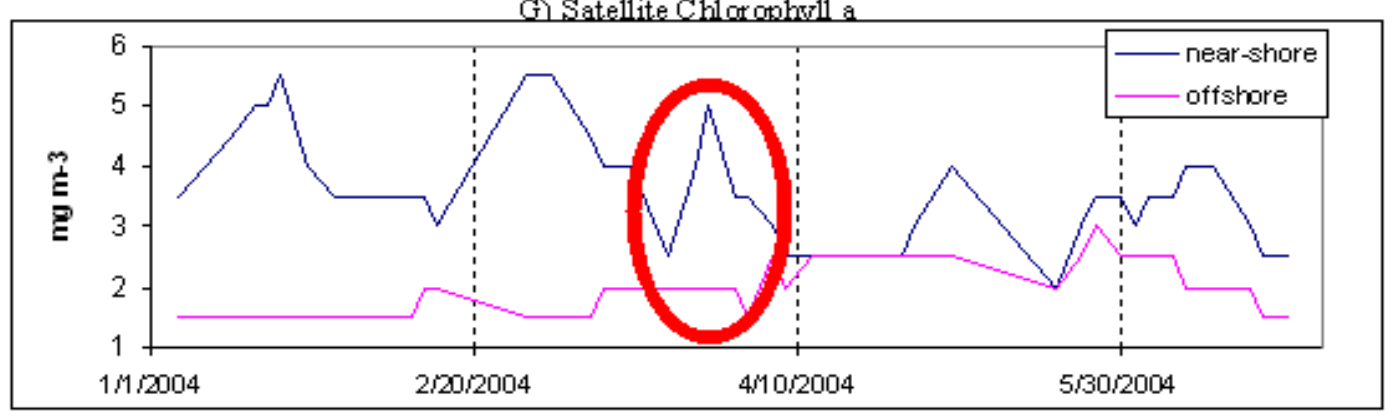

Figure 7. A through F) Oceansat-1 OCM images taken from 3/21/2004 to 4/6/2004 showing chlorophyll a accumulation. G) Graphical extrapolation of chlorophyll a concentration vs. time. Red circle shows chlorophyll a concentrations concurrent to images A through F. (Nearshore) measurements (blue) were reported from NOAA temperature gauge 9412110 while (offshore) measurements (pink) were reported from NOAA buoy 46062. 
A) Satellite Chlorophyll a
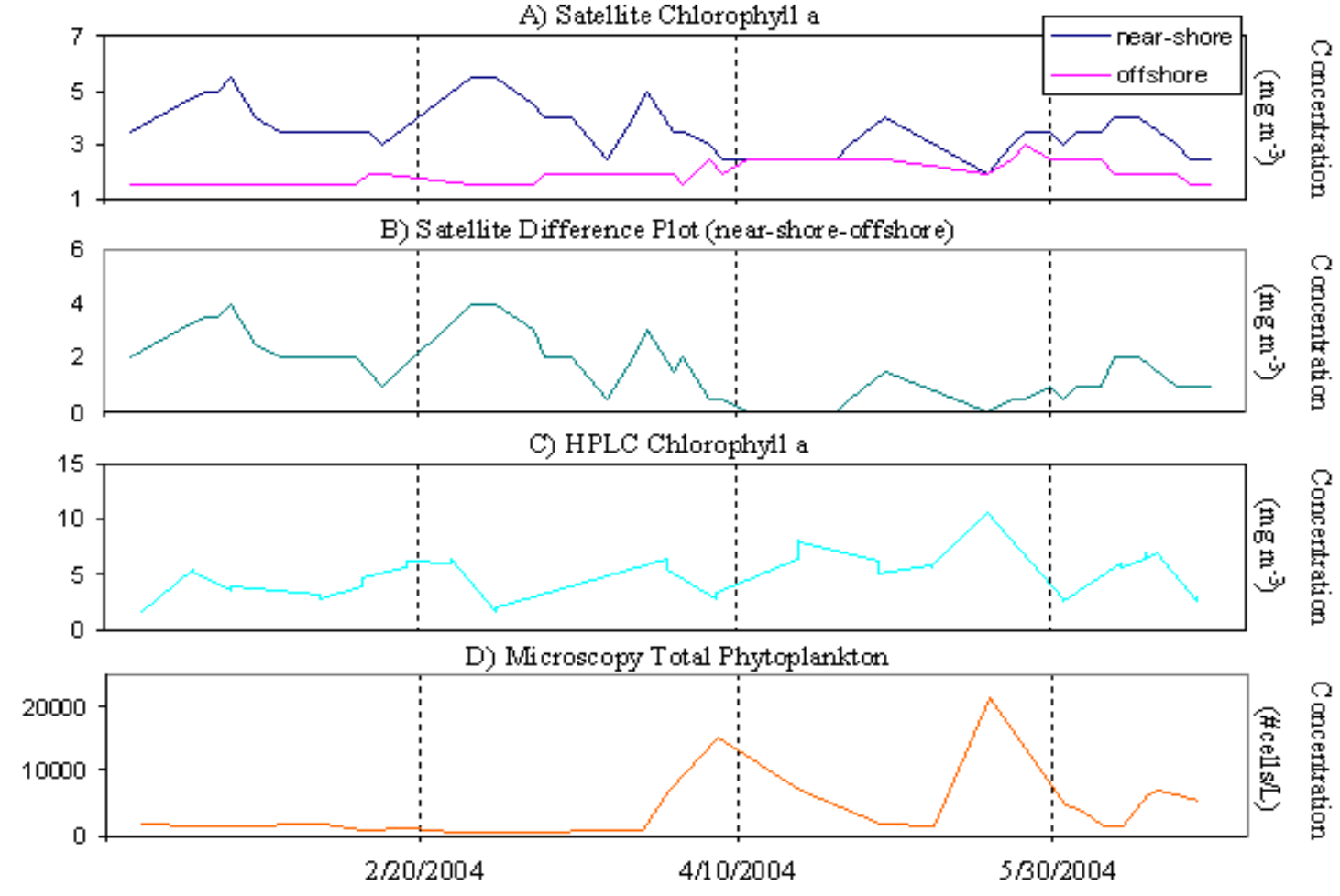

Figure 8. Biomass estimates reported from 1/1/2004 to 6/22/2004. A) Satellite chlorophyll a concentration. (Nearshore) measurements (blue) were reported from NOAA temperature gauge 9412110 while (offshore) measurements (pink) were reported from NOAA buoy 46062. B) Satellite chlorophyll a difference plot. Temperature is reported as (nearshore-offshore). C) HPLC chlorophyll a concentration. D) Total phytoplankton abundance from microscopic identification. 


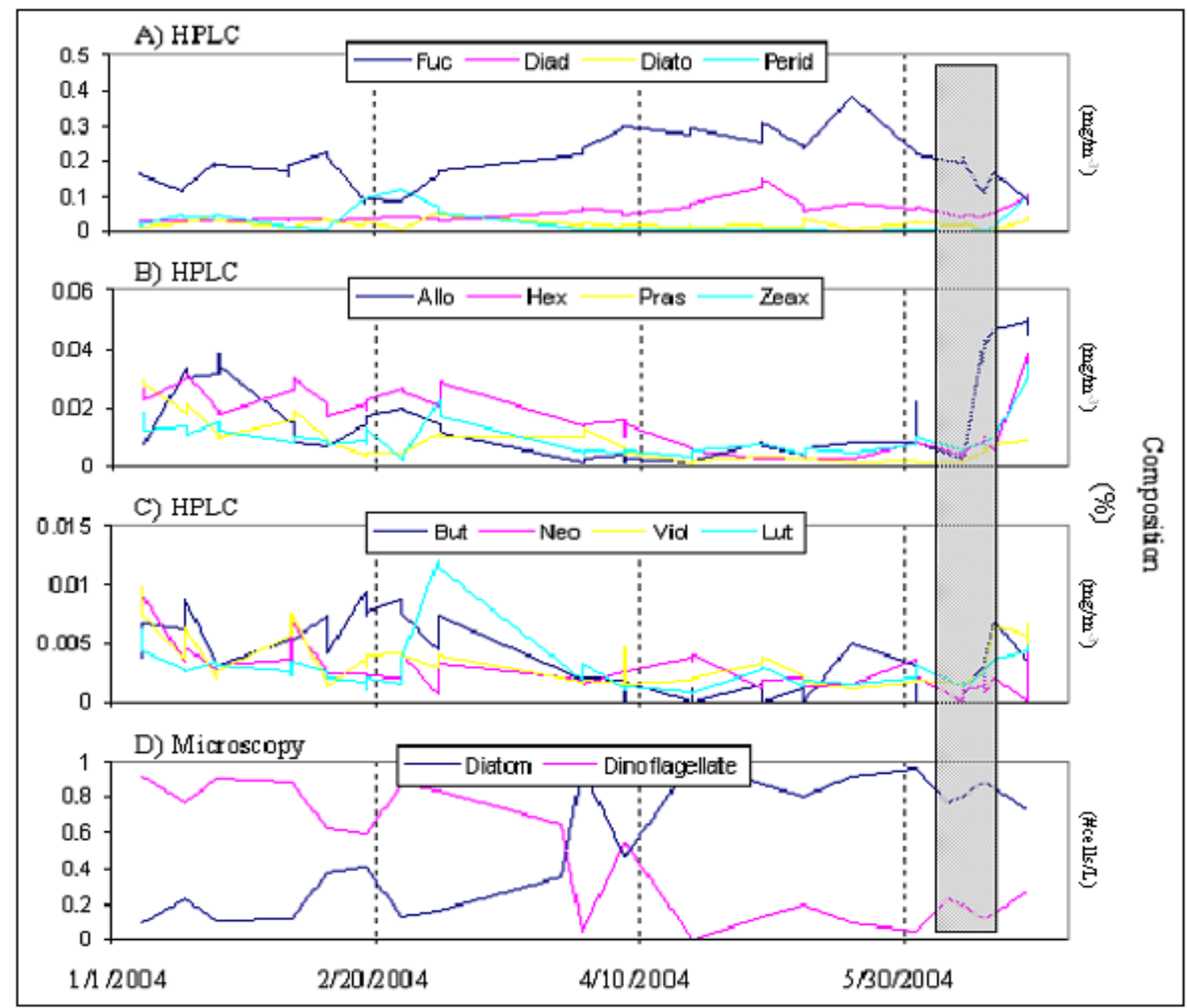

Figure 9. Community structure from 1/1/2004 to 6/22/2004 reported as normalized percent composition. A) High Performance Liquid Chromatography (HPLC), percent composition of fucoxanthanin (Fuc), diadinoxanthanin (Diad), diatoxanthanin (Diato), and peridinin (Perid). (B). HPLC percent composition of alloxanthin (Allo), hexanoyloxyfucoxanthin (Hex), prasinoxanthin (Pras), and zeaxanthin (Zeax). C). HPLC percent composition of butanoyloxyfucoxanthin (Hex), neoxanthin (Neo), violaxanthin (Viol), and lutenin (Lut). D) Percent composition of diatoms and dinoflagellates from microscopic identification. Shaded gray area shows REMUS deployment period $6 / 4 / 2004$ to $6 / 16 / 2004$. 
A) 040604 Temperature
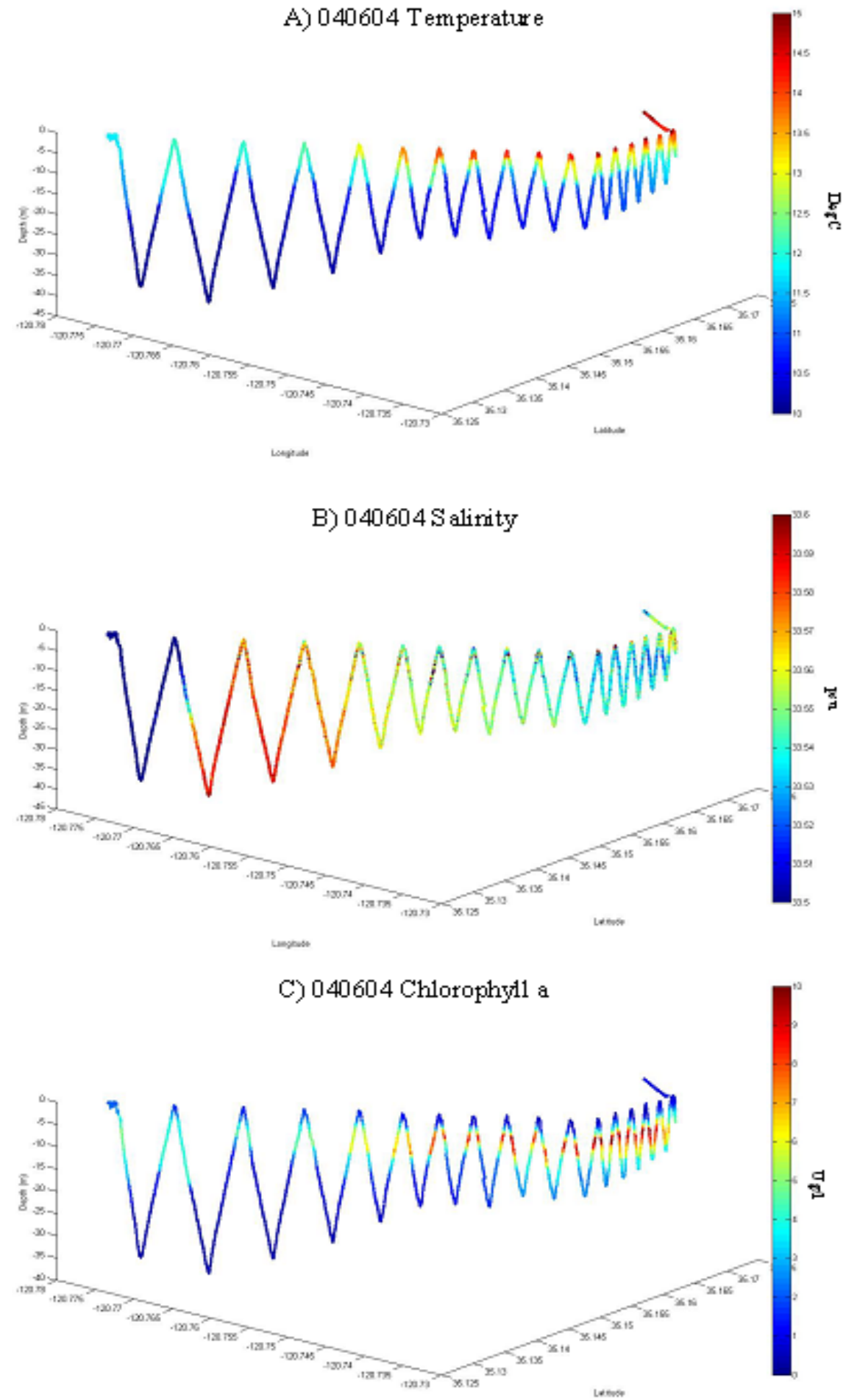

Figure 10. REMUS data reported on 6/4/2004 showing 3-dimensional distribution of A) Temperature, B) Salinity, and C) Chlorophyll a. 

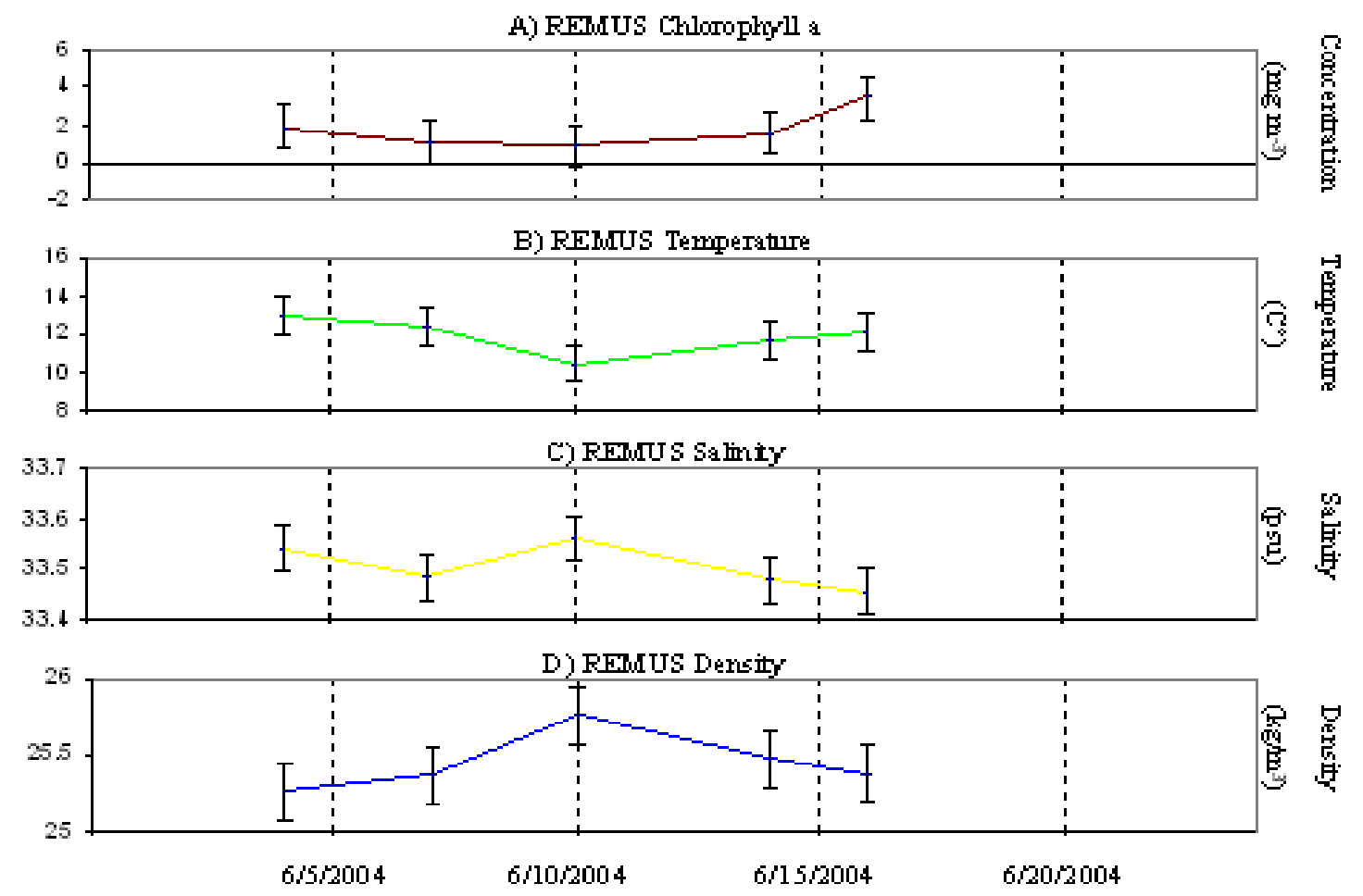

Figure 11. REMUS data reported during our study period showing leg 5 and 6 average values. A) Chlorophyll a, B) Temperature, C) Salinity, and D) Density. 


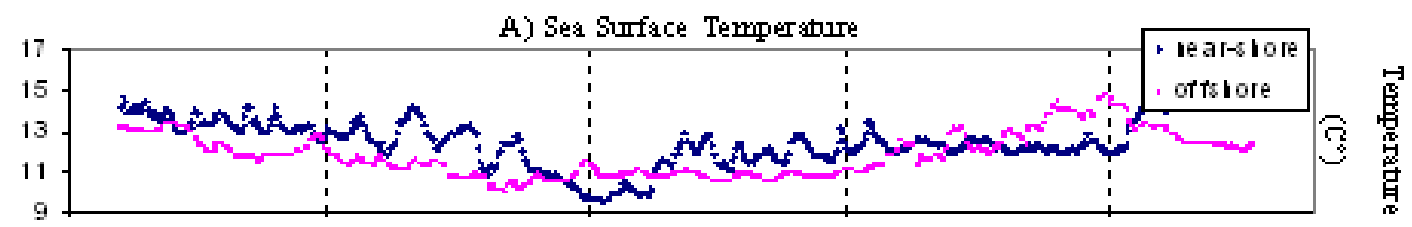

B) Sea Sufface Temperature Difference Plot (ne ar-shore-offshore)
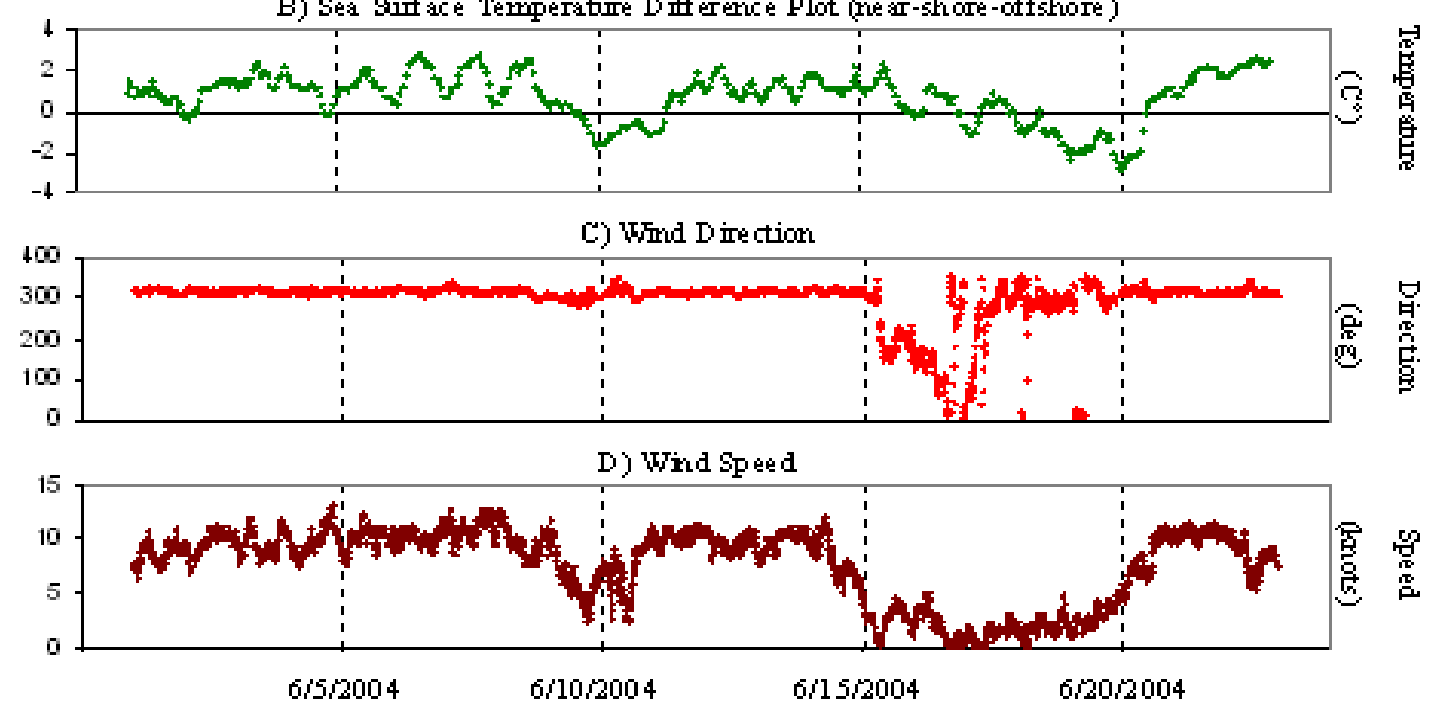

Figure 12. Physical data reported during our study period from 6/1/2004 to 6/22/2004. A) SST, nearshore (blue) reported from NOAA temperature gauge 9412110, offshore (pink) reported from NOAA buoy 46062. B) SST difference plot (nearshore-offshore), C) Wind direction form NOAA buoy 46062 , and D) Wind speed from NOAA buoy 46062. 

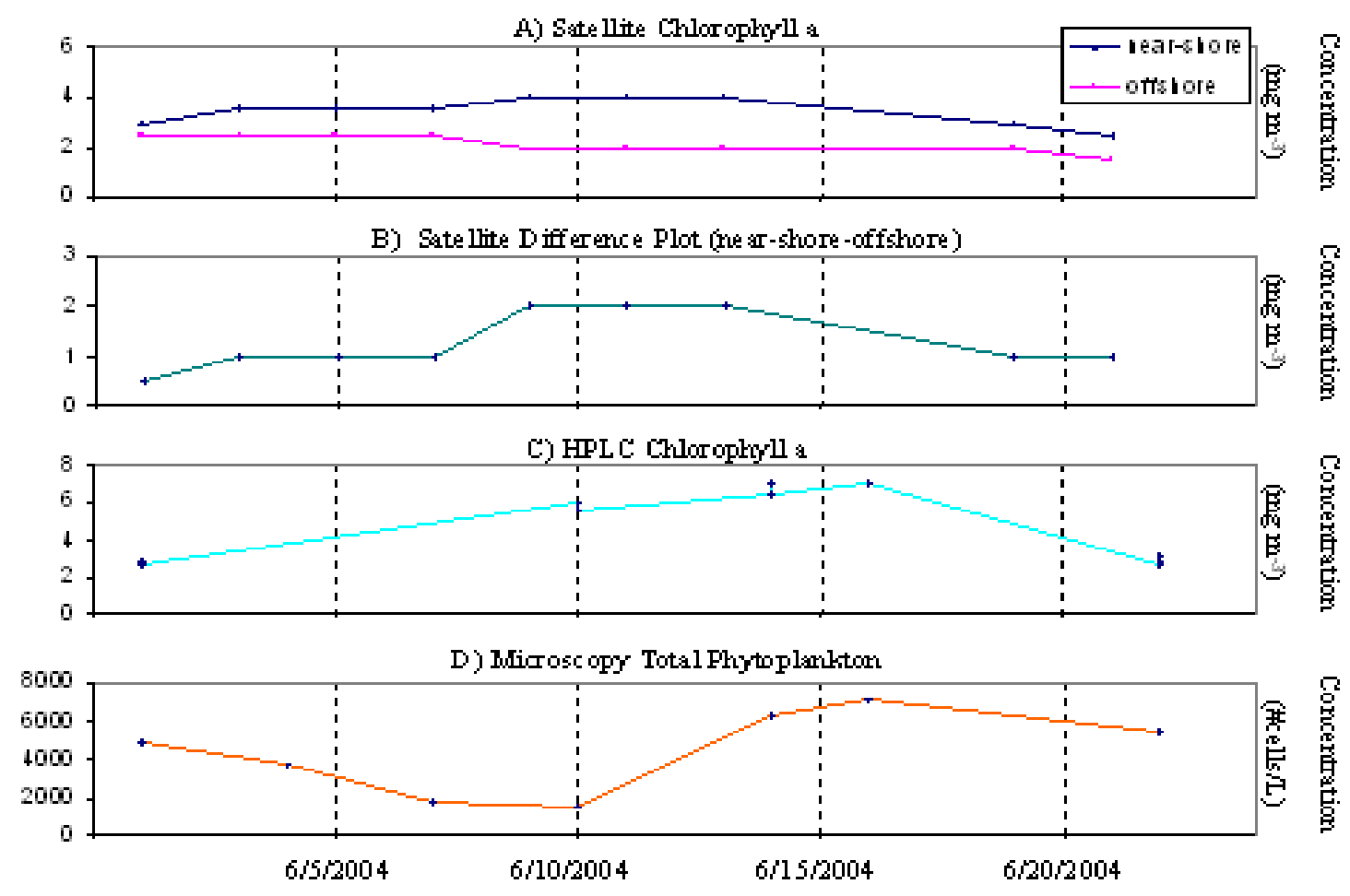

Figure 13. Biological data reported during our study period from 6/1/2004 to 6/22/2004. I) Satellite chlorophyll a concentration, J) Satellite chlorophyll a difference plot (nearshore-offshore), K), HPLC chlorophyll a concentration, and L) Microscopy total phytoplankton. 

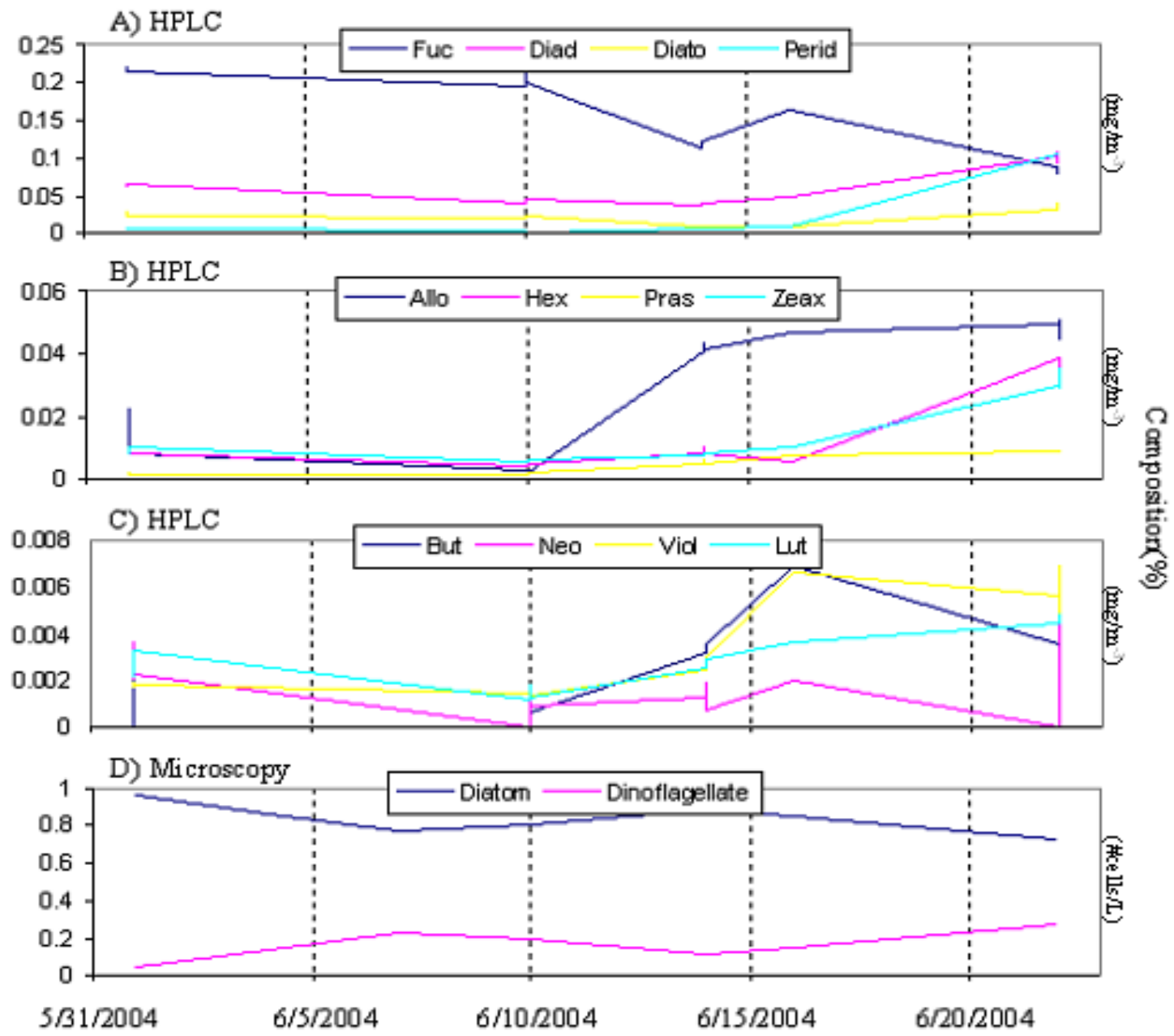

Figure 14. Community structure during our study period from 6/1/2004 to 6/22/2004 reported as normalized percent composition. A) High Performance Liquid Chromatography (HPLC), percent composition of fucoxanthanin (Fuc), diadinoxanthanin (Diad), diatoxanthanin (Diato), and peridinin

(Perid). (B). HPLC percent composition of alloxanthin (Allo), hexanoyloxyfucoxanthin (Hex), prasinoxanthin (Pras), and zeaxanthin (Zeax). C). HPLC percent composition of butanoyloxyfucoxanthin (But), neoxanthin (Neo), violaxanthin (Viol), and lutenin (Lut). D) Percent composition of diatoms and dinoflagellates from microscopic identification. 

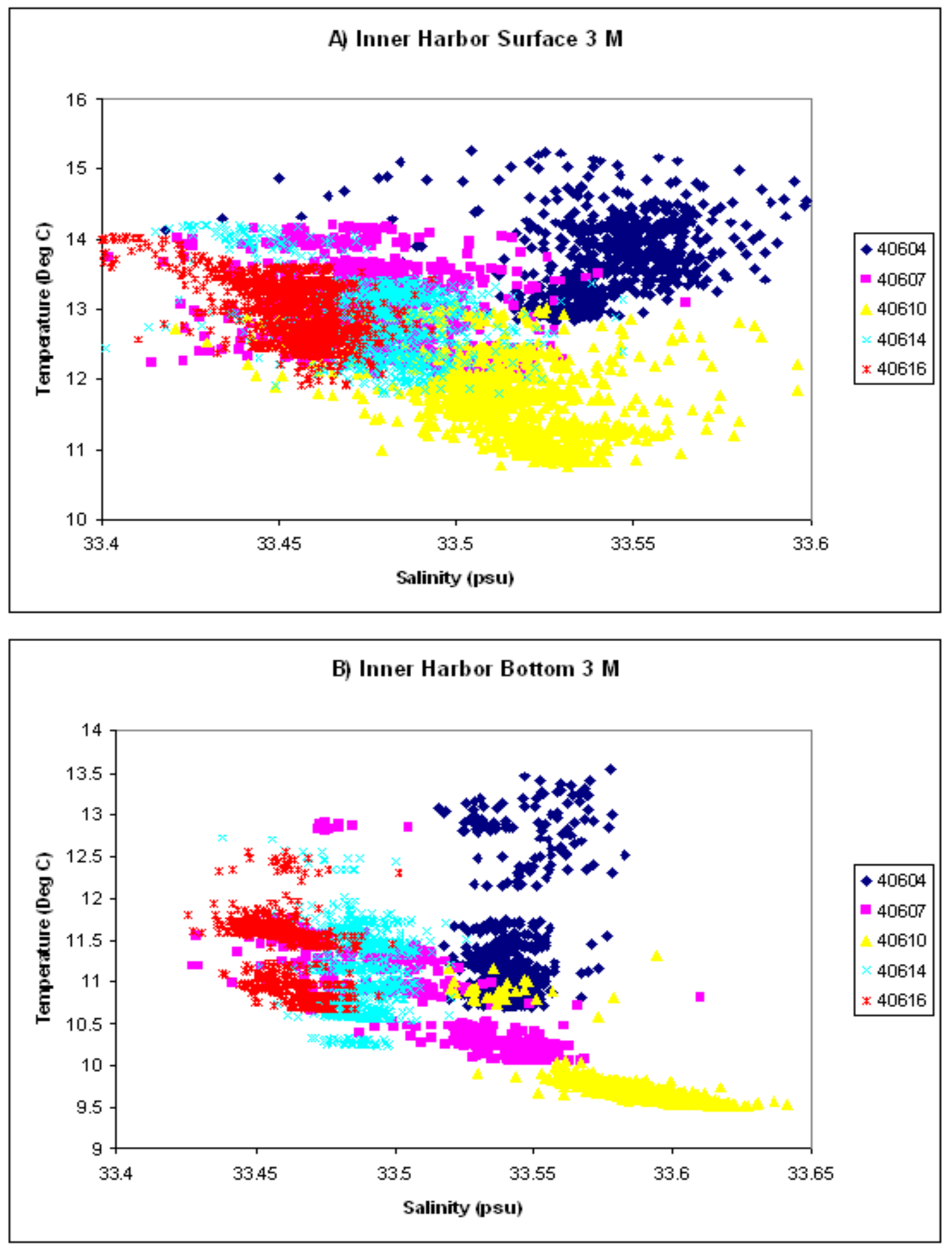

Figure 15. REMUS Temperature vs. Salinity plots. A) Data taken from the surface $3 M$ of the inner harbor return. B) Data taken from bottom 3M of the inner harbor return. Data shows distinct upwelling event on 6/10/2004 (yellow), followed by poleward water replacement on 6/14/2004 and 6/16/2004 (turquoise, red). 


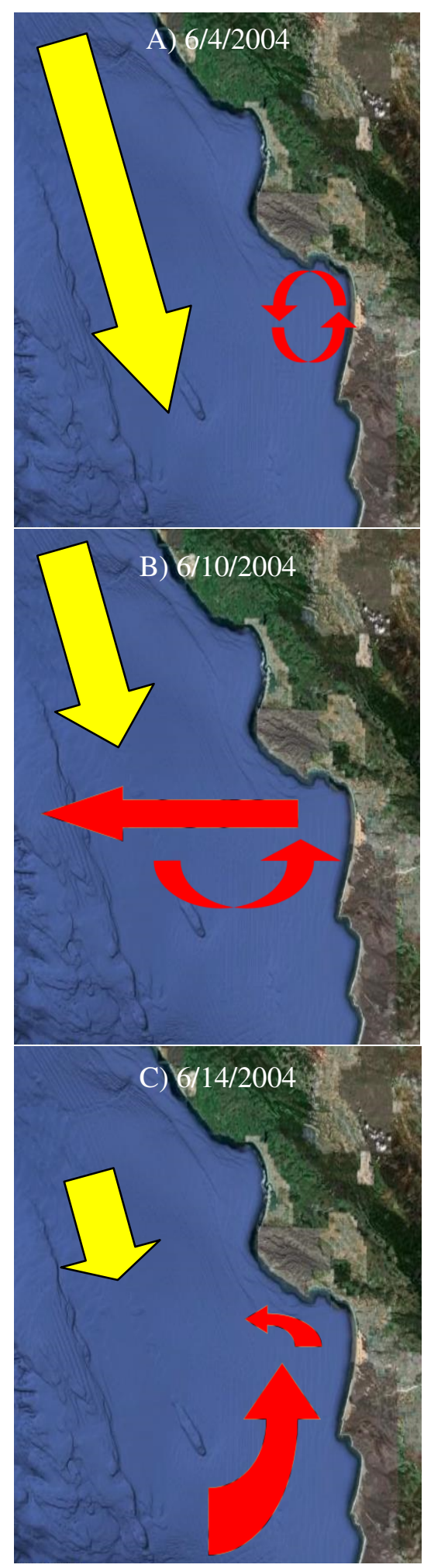

Figure 16. Diagram of water movement based on described mechanism. Reported dates determined by REMUS salinity vs. temperature data. Wind direction shown in yellow and water movement shown in red. A) Strong north-west wind forcing and retention B) Declining wind forcing and replacement by cool saline upwelled waters $C$ ) Weak wind forcing and replacement by warm fresh poleward movement. 


\section{WORKS CITED}

Abbott, M. R., K. H. Brink, C. R. Booth, D. Blasco, L. A. Codispotti, P. P. Niiler, and S. R. Ramp. 1990. Observations of phytoplankton and nutrients from a Lagrangian drifter off northern California. J. Geophys. Res. 95, 9393-9409.

Alldredge, A. and C.C. Gotschalk. 1989. Direct Observations of the Mass Flocculation of Diatom Blooms: Characteristics, Settling Velocities and Formation of Diatom Aggregates. Deep Sea Res. 36:2, 159-171.

Andersen, R.A., R.R. Bidigare, M.D. Keller, and M. Latasa. 1996, A comparison of HPLC pigment signatures and electron microscopic observations for oligotrophic waters of the North Atlantic and Pacific Oceans. Deep Sea Res. 43:2/3, 517-537.

Bakun, A. and C.S. Nelson. 1977. Climatology of upwelling related processes off Baja California. Calif. Coop.Oceanic Fish.Invest.Rep. 19,107-127.

Blasco, D. 1978. Observations on the diel migration of marine dinoflagellates of the Baja California coast. Mar. Bio. 46:41-47.

Breaker, L. C. 1986. Oceanic Variability off the Central California Coast. Progress in Oceanogr. 17:1, 61-135.

Brink, K., and T. Cowles. 1991. The coastal transition zone program. J. Geophys. Res. 96, 14637-14647. 
Chavez, F.P., B.B. Marinovic, D.A. Croll, N. Gong, and S.R. Benson. 2000. Effects of the 1997-1997 El Nino and La Nina events on zooplankton abundance and euphausid community composition within the Monterey Bay coastal upwelling system. Progress in Oceanogr. 54: 1-4, 265-277.

Cloern, J.E. 1996. Phytoplankton bloom dynamics in coastal ecosystems: A review with some general lessons from sustained investigation of San Francisco Bay, California. Reviews of Geophys. 34:2, 127-168.

Collins, C.A., J.T. Pennington, C.G. Castro, T.A. Rago, and F.P. Chavez. 2003. The California Current System off Monterey, California: Physical and biological coupling. Deep-Sea Res. 50, 2389-2404.

Cushing, D.H. 1959. Grazing by Herbivorous Copepods in the Sea. J. Mar. Sci. 32:1, 7082.

Durbin, E.G. 1974. Aspects of the Biology of resting spores of Thalassiosira nordenskioeldii and Detonula confervacea. Mar.Biol. 45:1, 31-37. 
Fawcett, A., G. Pitcher, S. Bernard, A. Cembella, and R. Kudela. 2007. Contrasting wind patterns and toxigenic phytoplankton in the southern Benguela upwelling system. Mar. Ecol. Prog. Ser. 348, 19-31.

Gilstad M.M, and E.A. Sakshaug. 1990. Growth rates of ten diatom species from the Barents Sea at different irradiances and day lengths. Mar. Ecol. Prog. Ser. 64, 169-173.

Graham, W. M., J. G. Field, and D. C. Potts. 1992. Persistent "upwelling shadows" and their influence on zooplankton distributions. Mar. Bio. 114, 561-570.

Graham, W.M., and J.L. Largier. 1997. Upwelling shadows as nearshore retention sites: The example of northern Monterey. Continental Shelf Res. 17, 509-532.

Iizuka, S., and K. Mine. 1983. Maximum Growth Rate of Gymnodinium sp. (Type 65), a Red Tide Dinoflagellate, Expected under Culture Conditions. Bulletin of Plankton Society of Japan. 30: 2, 139-146.

Jassby, A.D., and C.R. Goldman. 1974. Loss rates from a lake phytoplankton community. Limen. and Oceanogr. 19:4, 618.

Kahru, M., B. G. Mitchell, A. Diaz, and M. Miura. 2004. MODIS detects a devastating algal bloom in Paracas Bay, Peru. Eos Trans. 85:45, 465. 
Kelly, K.A. 1985. The influence of winds and topography on sea surface temperature patterns over the northern California slope. J. Geophys. Res. 90, 11783-11798.

Kudela, R.M., F.P. Chavez. 1997. Multi-platform remote sensing of new production in central California during the 1997-1998 El Nino. Progress in Ocenaog. 54:1-4, 233-249.

Kudela, R.M., B.S. Neil, and J.A. Barth. 2008. Controls and Mechanisms of Phytoplankton Productivity in Coastal Upwelling Waters of the Northern California Current System. Oceanogr. 22:4, 46-59.

Langolis, G. A. and P. Smith. 2000. Beyond the Golden Gate- Oceanography, Geology, Biology and environmental issues in the gulf of the Farallones: US Geological Survey. US Department of the Interior. 123-132.

Largier, J. L., B. A. Magnell, and C. D. Winant. 1993. Subtidal circulation over the northern California shelf. J. Geophys Res. 98, 18147-18179.

Largier, J. L. 2004. The importance of retention zones in the dispersion of larvae. American Fisheries Society Symposium. 42, 105-122. 
Lassiter, A.M., R.C. Wilkerson, and V.E Houge. 2005. Phytoplankton assemblages in the CoOP-WEST coastal upwelling area. Deep Sea Res. 53:2, 3063-3077.

LeBlond, P.H., M.,Helai, F. Doherty, and S. Pond. 1990. Deep and Intermediate Water Replacement in the Straight of Georgia. Atm.-Ocean. 29:2, 288-312.

Marín, V. H., Ruben Escribanob, Luisa E. Delgadoa, Gonzalo Olivaresa and Pamela Hidalgo. 2001. Nearshore circulation in a coastal upwelling site off the Northern Humboldt current system. Continental Shelf Res. 21, 1317-1329.

Marin, V.H., L.E. Delgado, and R. Escribano. 2003. Upwelling Shadows at Mejillones Bay (northern Chilean coast): a remote sensing in situ analysis. Invest. Mar. 31:2, 47-55.

Michaelsen, J., X. Zhang, and R. C. Smith. 1988. Variability of pigment biomass in the California Current as determined by satellite imagery, 2. Temporal variability. $J$. Geophys. Res. 93:10, 883-10,896.

Miller, A.J., J. C. McWilliams, N. Schneider, J. S. Allen, J. A. Barth, R. C. Beardsley, F. P. Chavez, T. K. Chereskin, C. A. Edwards, R. L. Haney, K. A. Kelly, J. C. Kindle, L. N. -Ly, J. R. Moisan ${ }^{1}$, M. A. Noble, P. P. Niiler, L. Y. Oey, F. B. Schwing, R. K. Shearman, and M. S. Swenson. 1999. Observing and Modeling 
the California Current System. Eos, Transactions, American Geophysical Union. $80,533-539$.

Millie, D. F., H. W. Pearl and J. P. Hurley. 1993. Micoroalgal pigment assessments using high-performance liquid chromatography: a synopsis of organismal and ecological applications. Can. J. Fish. Aquat. Sci. 50, 2513-2527.

Moita, M. T., S. Palma, P. B. Oliviera, T. Vidal, A. Silva, and M. G. Vilarinho (2006), The return of Gymnodinium catenatum after 10 years: Bloom initiation and transport of the Portuguese coast paper presented at 12th International Conference on Harmful Algae, Int. Soc. for the Stud. of Harmful Algae, Copenhagen, 4-8 Sept.

Moline, M.A., D.L. Woodruff and N.R. Evans. 2007. Optical Delineation of Benthic Habitat using an Autonomous Underwater Vehicle. J. Field Robotics. 24: 6, 461471.

Newton, J. 2002. Analysis of Phytoplankton Pigments: Determination of Chlorophyll a www.courses.washington.edu/ocean220/misc/Chla_method_newton.pdf

Parrish, R. R., and M. J. Tegner. 2001. California's Variable Ocean Environment. California's Living Marine Resources: A Status Report. Cal. Fish and Game. 2128. 
Patten, B.C. 1968. Mathematical Models of Plankton Production. International Review of Hydrobiol. 53:3, 357-408.

Penven, P., B. Blanke, and C. Roy. 2002. Linking wind and interannual upwelling variability in a regional model off the southern Benguela. Geophys. Res. Letters. 29:0, 1029-1033.

Pitcher, G. C., and G. Nelson. 2006. Characteristics of the surface boundary layer important to the development of red tide on the southern Namaqua shelf of the Benguela upwelling system. Limnol. Oceanogr. 51, 2660- 2674.

Rosenfeld, L. K., F. B. Schwing, N. Garfield, and D. E. Tracy. 1994. Bifurcated flow from an upwelling center: A cold water source for Monterey Bay. Cont. Shelf Res. $14,931-964$.

Ryan, J., F. Chavez, and J. Bellingham, 2005. Physical-biological coupling in Monterey Bay, California: topographic influences on phytoplankton ecology. Mar. Ecol. Prog. Ser. 287, 23-32.

Ryan, J. P., M. A. McManus, J. D. Paduan, and F. P. Chavez. 2008. Phytoplankton thin layers within coastal upwelling system fronts. Mar. Ecol. Prog. Ser. 354, 21- 34. 
Schrader, C.G. 1981. Seasonal Cycles of Phytoplankton in Relation to the Hydrography of Monterey Bay. Moss Landing Marine Laboratories Technical Publication. $81: 2$

Schwarzlose, R.A. 1972. Release and recovery records of drift bottles in the California Current region, 1955 through 1971. California Cooperative Fisheries Atlas No. 16, Marine fisheries Committee, State of California.

Seiler, W. L., and A. J. Scott 1964. Biotic Assemblages South-Central Texas Coast. Biol. Soc. Geol. Mexicana. 27:1, 17-25.

Slaughter, A.M., S.M. Bollens, and G. R. Bollens. 2006. Grazing impact of mesozooplankton in an upwelling region off northern California, 2000-2003. Deep Sea Res. 53:25-26, 3099-3115.

Smayda T.J. 2002. Turbulence, watermass stratification and harmful algal blooms: An alternative view and frontal zones as pelagic seed banks. Harmful Algae 1, 95112.

Strub, P.T, and C. James. 1987. The large-scale summer circulation of the California Current. Geophys. Res. Letters. 22:3, 207-210.

Suzuki, K., N. Handa, H. Kiyosawa and J. Ishizaka 1995. Distribution of the 
prochlorophyte Prochlorococus in the central Pacific Ocean as measured by HPLC. Limnol. Oceanogr, 40, 983-989.

Suzuki, K., N. Handa, H. Kiyosawa and J. Ishizaka 1997. Temporal and spatial patterns of phytoplankton pigments in the central Pacific Ocean during the boreal summers of 1992 and 1993. J. Oceanogr. 53, 383-396.

Tont, S. A. 1976. Short-period climatic fluctuations: effects on diatom biomass. Science. 194, 942-944.

Tont, S. A. 1981. Temporal variations in diatom abundance off southern California in relation to surface temperature, air temperature and sea level. J. Mar. Res. 39, $191-201$

Tont, S. A. 1989. Climatic change: response of diatoms and dinoflagellates. Aspects of climate variability in the Pacific and western Americas. Geophys. Monogr. 55, $161-163$.

Traganza E.D, J.C. Conrad, and L.C. Breaker 1981. Satellite observations of a cyclonic upwelling system and giant plume in the California current. In Coastal Upwelling, Richards FA (ed.). American Geophysical Union: Washington, DC; 228-241. 
UNESCO. 2003. The Integrated, Strategic Design Plan for the Coastal Oceans Observation Module of the Global Ocean Observing System. GOOS Report No. 125. IOC Information Documents Series No. 1183. UNESCO, Paris, France, 190.

Walsh, J.J. 1991. Importance of continental margins in the margin biochemical cycling of carbon and nitrogen. Nature 350, 53-55.

Wing, S.R., L.W. Botsford, S.V. Ralston, and J.L. Largier. 1998. Meroplanktonic distribution and circulation in a coastal retention zone of the northern California upwelling system. Limnol. Oceanogr. 43, 1710-1721.

Yoder, J.A., S.G Ackleson, R.T. Barber, P. Flament, and W. M. Balch. 1994. A line in the sea. Nature 371, 689-692.

Zemba, J., and C. A. Friehe. 1987. The Marine Atmospheric Boundary Layer Jet in the Coastal Ocean Dynamics Experiment. J. Geophys, Res. 92, 1489-1496. 